\title{
El sueño oriental. \\ O la dificultad de la incorporación del territorio amazónico al estado nacional en Ecuador
}

\author{
Javier Martínez-Sastre
}

\section{RESUMEN}

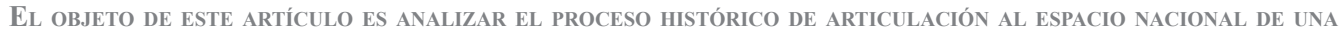
región de la baja Amazonía ecuatoriana, la cuenca baja del Curaray. Tratamos de demostrar que lo

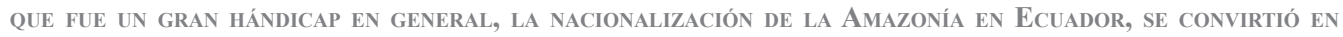
uNA IMPOTENCIA POR PARTE del ESTAdo EN REgIONES ALEJADAS COMO ESTA. SE TRATA de UN TERRITORIO CON UNA HISTORIA DINÁMICA QUE, TRAS LA EXPANSIÓN DE LA ACTIVIDAD CAUCHERA QUE COMIENZA EN EL 1980, SE DESPUEBLA CUANdo Ésta ENTRa en CRisis (Alrededor de 1920). A partir de los años Setenta del pasado siglo fue objeto DE UN PROYECTO ESTATAL DE RECOLONIZACIÓN DADA SU IMPORTANCIA GEOESTRATÉGICA, PROYECTO QUE POR DIVERSAS RAZONES NO LLEGó A EJECUTARSE. NO SERÁ HASTA LA DÉCADA DE LOS NOVENTA QUE ESA APROPIACIÓN DEL TERRITORIO SE HARÁ EFECTIVA, PERO ESTA VEZ EN MANOS DE UNAS ÉLITES INDÍGENAS QUICHUAS QUE, CON UN DISCURSO ÉTNICO Y AMBIENTALISTA, OBTENDRÁN CUANTIOSOS RECURSOS DE LA COOPERACIÓN INTERNACIONAL Y CONSIGUEN ARTICULAR UNA RED de COMUNIDADES QUICHUAS EN ESE TERRITORIO. El PROCESO HISTÓRICO DE NACIONALIZACIÓN DE ESTE TERRITORIO DE GRAN IMPORTANCIA ECONÓMICA CONSTITUYE EL EJE VERTEBRADOR DE ESTE ARTÍCULO.

Palabras clave: Amazonía - Ecuador - historia - etnicidad - territorio.

\section{RESUMEN}

The AIM OF THIS ARTICle IS TO ANALYZE THE HISTORICAL PROCESS OF THE ARTICULATION OF NATIONAL SPACE IN A region of the low Ecuadorian Amazon, the lower basin of the Curaray River. We try to prove that the NATIONAlization of THE AMAZON IN ECUAdor -A GREAT HANDiCAP IN GENERAL- BECAME A HOPELESS SITUATION FOR THE STATE IN OUTLYING REGIONS LIKE THIS. IT IS A TERRITORY WITH A DYNAMIC HISTORY THAT, AFTER THE EXPANSION OF RUBBERING ACTIVITY WHICH BEGAN IN 1980, WAS DEPOPULATED WHEN THIS ACTIVITY WENT INTO CRISIS (AROUND 1920). SiNCE THE 1970'S SEVENTIES THIS AREA WAS THE SUBJECT OF A STATE RESETTLEMENT PROJECT BECAUSE OF ITS GEOSTRATEGIC IMPORTANCE. For VARIOUS REASONS THE PROJECT WAS NEVER EXECUTED. IT WOULDN'T BE UNTIL THE 1990S THAT THE APPROPRIATION OF THIS TERRITORY WOULD BE EFFECTIVE, THIS TIME IN THE HANDS OF INDIGENOUS QUICHUA ELITES WHO, WITH AN ETHNIC AND ENVIRONMENTALIST DISCOURSE, WOULD RECEIVE SUBSTANTIAL RESOURCES FROM INTERNATIONAL CORPORATIONS AND MANAGE TO ARTICULATE A NETWORK OF QUICHUA COMMUNITIES IN THE TERRITORY. THE BACKBONE OF THIS ARTICLE IS THE HISTORICAL NATIONALIZATION PROCESS OF THIS TERRITORY OF GREAT ECONOMIC IMPORTANCE.

Palabras clave: Amazonia - Ecuador - history - ethnicity - territory.

1 Centro de Prospectiva Estratégica (CEPROEC) - Instituto de Altos Estudios Nacionales (IAEN). Investigador invitado en la Universidad Nacional de Chimborazo (UNACH), Ecuador. Correo electrónico: jamarsas@hotmail.com 
$\mathrm{D}$ urante la época colonial la Amazonía fue un territorio de difícil acceso, una región caracterizada durante la mayor parte del tiempo por el olvido y el abandono, pero fuente de mitos y creencias. Un área, en definitiva, en donde la ilusión del paraíso, el oro, las riquezas y el poder (el mítico Dorado), se convertía muy frecuentemente en un infierno indomable e inconquistable. Esta visión perduró hasta bien entrada la época republicana, cuando el siempre mítico "Oriente" se convirtió en una obsesión provocada por la incapacidad de incorporarla al Estado nacional, hecho que no se produjo hasta mediados del siglo XX cuando, por su inserción a la economía global vía extractivismo petrolero, logró conseguirse tan deseado anhelo. Es lo que hemos llamado "el sueño oriental", o la dificultad y la obsesión por incorporarla a los dominios de Quito.

En este artículo bucearemos por ese sueño, analizando cómo se llevó a cabo la nacionalización del mítico Oriente ecuatoriano, pero además lo haremos desde un lugar de la baja Amazonía o Amazonía interior; región que, por su situación de lejanía e incomunicación, tuvo mucha más dificultad de ser integrada al Estado. Se explicará cómo fue la articulación de la cuenca baja del Curaray al espacio nacional, situándola primero en la evolución general de la Amazonía para después analizar los procesos particulares de la misma. El objetivo es demostrar la dificultad que el Estado ecuatoriano ha tenido de nacionalizar la Amazonía en general y la impotencia que ha demostrado intentando integrar regiones del interior. Así, en esta región concreta los planes estatales para su colonización y articulación fueron infructuosos, y tuvo que ser, como veremos, la acción de élites indígenas en un momento de emergencia del actor étnico las que lograron materializar dicho proyecto.

\section{La impotencia colonial}

En los inicios de la instauración de la colonia española en la región equinoccial americana, se establece el primer frente de colonización amazónica, relacionado con un breve pero intenso boom de la minería aurífera en el piedemonte andino. Se trata de un ciclo muy corto, que va desde la cuarta década del siglo XVI hasta finales del mismo siglo, de penetración masiva y brutal. Este ciclo finaliza bruscamente con el fin del auge minero, dejando tras de sí el abandono casi absoluto de esta región por parte de la sociedad civil blanco-mestiza y una fuerte caída demográfica provocada por las epidemias, los reclutamientos forzados y las revueltas (Deler, 2007: 80-81). De esta manera, potenciada por el abandono, nos encontramos con una de las consecuencias del primer frente colonizador más decisivas de cara a la historia de la región en estos últimos cuatro siglos: la transformación de esta área en una zona de frontera, con todo lo que ello implica. El proceso de ruptura de las tierras altas con las del Oriente se consolidó en esta época, aunque había comenzado en parte con los incas, que empezaron a desmantelar algunos de los sistemas de alianza verticales que habían existido históricamente y fueron los primeros en formular la dicotomía entre sierra civilizada y barbarie selvática (Taylor, 1994: 23). En este período corto de tiempo, la intensidad de la penetración española acabó con lo que quedaba del tejido de relaciones preincaicas. Con la retirada española de estos asentamientos y la gran caída demográfica en el declive andino y la alta Amazonía, se completó un proceso de ruptura entre tierras altas y bajas, estableciéndose esa frontera invisible que durante tanto tiempo ha persistido (y en parte todavía persiste).

Un segundo ciclo comienza a principios del siglo XVII y se consolida con la Cédula Real del 31 de diciembre de $1642^{2}$ y la creación de la Gobernación de Maynas. La impotencia e imposibilidad de la Audiencia de Quito de ejercer autoridad real alguna sobre los vastos

2 Esta Cédula Real confiaba la evangelización a los franciscanos en el norte, principalmente las gobernaciones de Mocoa y de Quijos, y a los jesuitas en el sur, en la Gobernación de Maynas. Hay que decir que la empresa más exitosa, y que aseguró por más de un siglo la presencia española y la vinculación de esta área con la Audiencia de Quito, fue la de los jesuitas. 

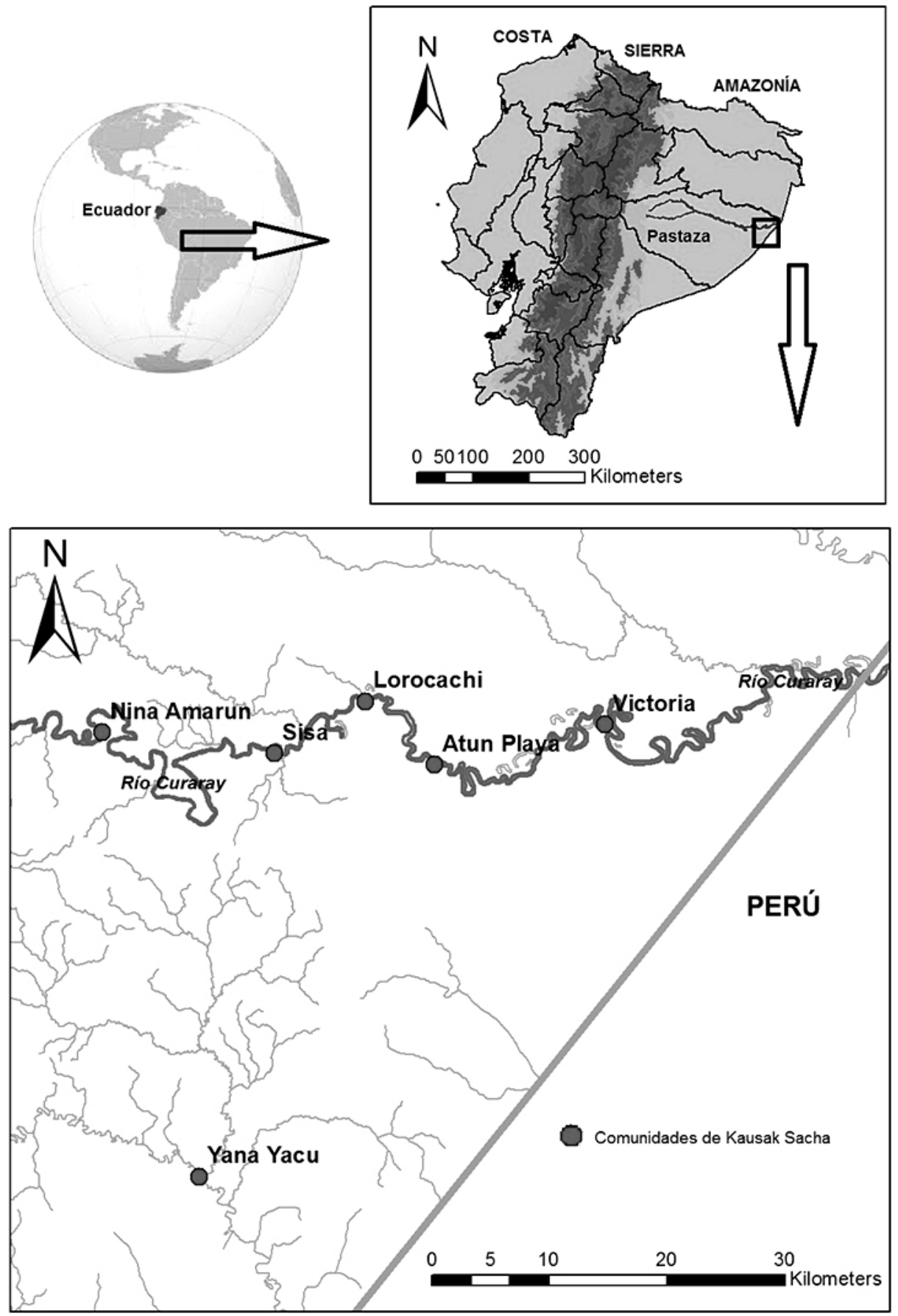

Figura 1: Situación de la Cuenca baja del Curaray. Fuente: elaboración propia con información del Instituto Cartográfico Militar de Ecuador (información base). Comunidades: Centro de InFORMACIÓn SocioAmbiental (CISA), IQBSS. 
territorios amazónicos que le habían sido asignados, llevó a la creación de un enorme, a la par que débil y vulnerable, frente misionero $^{3}$ vinculado a los jesuitas principalmente. Son dos las principales consecuencias de este ciclo: se produce una constante caída demográfica indígena vinculada principalmente a las epidemias introducidas por los españoles (Livi Bacci, 2012) y se introducen dinámicas sociales nuevas, entre ellas la que acabará conduciendo a una implantación y expansión del quichua en esta región.

Efectivamente, las misiones, siguiendo el modelo que habían usado en la sierra andina, utilizaron el quichua como lengua franca de evangelización, comenzando así un proceso de expansión de esta lengua en los territorios amazónicos. John Edwin Hudelson concibe este proceso de difusión del quichua en la época colonial como "la segunda etapa de expansión del quichua", después de la que se dio en la época incaica (1987: 23). Alrededor de este proceso, conocido comúnmente con el nombre de "quichuanización", existe una controversia entre los que afirman que podían existir ya dialectos quichuas en el área amazónica antes de la conquista (Whitten, 1987: 42-44) y entre los que opinan que no existen evidencias históricas que soporten esta teoría (Hudelson 1987: 26). Más allá de esta polémica, lo que sí parece muy claro es que el proceso que ha llevado a que el quichua se haya convertido en la lengua dominante en la Amazonía ecuatoriana hoy en día, comenzó en la colonia y concretamente en esta época intensa de misiones religiosas (Ibid.: 136-38), en el que la costumbre jesuítica de juntar en una misma misión una variedad de etnias diferentes supuso el "marco de creación de ciertos grupos étnicos coloniales y de la transformación de las relaciones inter-étnicas indígenas, correlativas a estos procesos de etnogénesis" (Taylor, 1994: 19). Este proceso es el que Blanca Muratorio ha definido como "simplificación etnocida", que provocó una "cristianización generalizada de los indígenas, por más superficial que ésta haya sido, y en su total quichuanización” (Muratorio, 1998: 81). La expansión del quichua estuvo, además, vinculada a otra de las consecuencias de la labor misionera de esta época: la expansión de la dicotomía civilizados/salvajes, que ya existía como hemos visto entre las tierras altas y bajas, al corazón mismo de la selva, siendo la evangelización y su consecuente quichuanización sinónimos de civilización (Taylor, 1994: 29).

Un tercer período se extiende desde la expulsión de los jesuitas (1767) hasta finales del siglo XIX y está caracterizado por el debilitamiento y fraccionamiento del frente misionero y un abandono total de este espacio por parte de las autoridades de Quito. Este abandono conlleva un relativo período de paz para las poblaciones indígenas que queda reflejado en un lento crecimiento demográfico y expansión de las que sobrevivieron (y con ellas la expansión del quichua $)^{4}$. Este ciclo perdura hasta más o menos 1880 , una vez ya proclamada la República ${ }^{5}$, cuando, como veremos a continuación, un nuevo acontecimiento sacudirá a la Amazonía.

3 Algunas cifras en su momento de auge antes de la expulsión pueden ser representativas de la magnitud de esta empresa misionera: una totalidad de una ciudad (Borja), 42 pueblos (en las riberas de los ríos Marañón, Napo, Pastaza, Bobonaza, y otros ríos caudalosos) y muchos pueblos menores, que son atendidos por un teniente de cura y 17 curas, comprendiendo a unas 14.000 personas (Porras, 1987: 50-52). El total de las misiones fundadas por los jesuitas entre 1632 y 1767 ascendieron a 152 (Hudelson, 1987: 128), cifra que si bien muestra la envergadura de la acción de los jesuitas, también indica las complicaciones y debilidades en el cometido, pues pocas de estas fundaciones lograban sobrevivir un tiempo largo.

4 Los yumbos de Quijos (término con el que se hacía referencia a un conjunto de grupos culturalmente diferentes, pero quichua-hablantes, de la región del mismo nombre) duplican su población aproximadamente desde 1767 hasta el boom cauchero de finales del XIX (Oberem, 1980: 48).

5 La proclamación de la República del Ecuador se trata de un período convulso (alzamientos, revueltas y guerras) que comienza con la "Revolución de Quito" (tentativa fracasada que transcurrió entre el 10 de agosto de 1809 y el 7 de diciembre de 1912), continúa con la independencia, primero de Guayaquil el 9 de octubre de 1820 y, después, de Quito tras la Batalla de Pichincha del 24 de mayo de 1822, y culmina con la proclamación de la independencia del Estado ecuatoriano de la Gran Colombia en 1830 (Deler, 2007: 124-129). En este periodo convulso la Amazonía quedaba en segundo plano profundizando el abandono a la que se la había sometido en la última etapa de la colonia. 


\section{EI frente colonizador del caucho}

A mediados del siglo XIX se produce otro frente de colonización propiamente dicho (después del siglo XVI) vinculado al boom cauchero ${ }^{6}$. Se trata de una colonización más lenta al principio y masiva en las dos últimas décadas del siglo, con unas consecuencias dramáticas para las poblaciones indígenas. Esta época significa la desaparición de muchas etnias y la potenciación de las dinámicas de quichuanización que habían comenzado en el siglo XVI.

Comerciantes peruanos, colombianos, franceses e italianos establecieron a partir de la década de 1850 explotaciones caucheras en territorio reclamado por Ecuador. La forma de explotación indígena varía según el tipo de explotación. El látex de la Hevea Brasiliensis, la goma más valiosa y cotizada, que se daba básicamente a las orillas del Putumayo y del Napo, se extrajo mediante la implantación de las grandes explotaciones de compañías monopolísticas, como la Casa Arana, capaces de montar verdaderos ejércitos esclavistas ${ }^{7}$. Las otras explotaciones, que se dedicaban básicamente a la balata (un látex menos cotizado en el mercado), se diseminaron por el resto del territorio (ver figura 2) y generalmente consistían en pequeños empresarios que movilizaban a unas decenas de trabajadores a lo sumo. Y es aquí donde se produce la paradoja más llamativa: las grandes explotaciones, más modernas técnicamente y más avanzadas desde el punto de vista de su organización, son las que hacen uso de la relación de producción más arcaica, la esclavitud; y las explotaciones más pequeñas, artesanales y atrasadas son las que experimentan con relaciones de producción más innovadores, basados en diferentes tipos de patronazgo, modelos que en las siguientes décadas se extenderán por la Alta Amazonía (Taylor, 1994: 43).

Las correrías $^{8}$ se generalizaron y, aun siendo el más salvaje y llamativo, no era el único procedimiento para "esclavizar". De hecho, muchos pequeños patronos recurrieron a las deudas, provocadas en su mayoría por repartos forzosos de productos altamente sobrevaluados, para el "enganche" o adquisición de mano de obra, que no olvidemos era muy escasa en este medio. La deuda se convertía así en un eficaz mecanismo de "esclavización" y con la "compra" de una deuda se podía adquirir a los indígenas (Barclay, 1998: 230). Se estableció así un verdadero sistema esclavista que provocó una gran caída demográfica en toda la Amazonía (Livi Bacci, 2012), entre ellas la ecuatoriana'. Aunque este sistema esclavista era el más llamativo, por brutal y siniestro, ya hemos visto que no era el único. Algunos grupos indígenas algo más alejados de la penetración directa, fueron obligados a trabajar en su misma tierra bajo sistemas de enganche más que de esclavismo. También existieron las migraciones temporales de gran cantidad de

6 Este boom comienza su despunte alrededor de 1880, para llegar a su punto culminante en la última década del siglo XIX. A principios del siglo XX se pierde el monopolio del caucho de la Amazonía, pues las plantaciones de los británicos en Malasia, Ceilán y en Africa subsahariana, realizadas con semillas extraídas ilegalmente de la propia Amazonía, empiezan a producir caucho de manera más eficaz y productiva. El precio, entonces, se viene abajo rápidamente y para 1914 ya se había agotado prácticamente dicho boom (Uribe, 2013: 36-41).

7 Las brutalidades ejercidas por la Casa Arana, del peruano Julio Cesar Arana, y las compañías inglesas fueron recogidas en un informe por el británico Roger Casement. Éste fue enviado como diplomático a Santos, Brasil, en 1906 y realizó su informe The Putumayo Black Book, que es enviado al parlamento inglés en 1912. En este informe deja "escrito en rojo sangre" el horror de las correrías para cazar indígenas, el maltrato, las torturas y el esclavismo. Según su informe ni en el Congo de Leopoldo, donde había estado unos años antes, había visto nada igual. Este informe es publicado en español por Abya Yala en 1985. Para una contextualización más general ver también Michael Taussig (1987), Pilar García Jordán (2001) y Delia del Pilar (2009).

8 Estas correrías o capturas de prisioneros indígenas viene de lejos, aunque se generalizaron y embrutecieron en la época del caucho. Ya para la década de 1850 Villavicencio los describe con detalle para las "tribus de Orejones, Angutéros, Mazanes, Santa Marias, y los Záparas del Curaray y Yasuní": "Estas incursiones que llaman correrías (...), Sorprenden las rancherías, matan a balazos a los que no andan listos en la fuga o a los que tratan de defenderse, cogen prisioneros a los muchachos y niños, y se marchan con ellos para venderlos en el Amazonas" (1858: 368). Incluso puede ser, siguiendo a Cabodevilla, que esas prácticas provenían de mucho antes de la llegada de los españoles. En un territorio extenso, hostil, poco poblado y con continuas guerras étnicas; este tipo de prácticas resultaban muy útiles para "limpiar" áreas donde establecerse y capturar esclavos, necesarios en lugares de tan baja densidad poblacional (Cabodevilla, 1999: 65, 85).

9 Para un exhaustivo análisis del fenómeno de traspaso de mano indígena desde la cuenca del Alto Napo a los países limítrofes de Perú y Colombia durante el boom cauchero consúltese el trabajo de Federica Barclay (1998). 


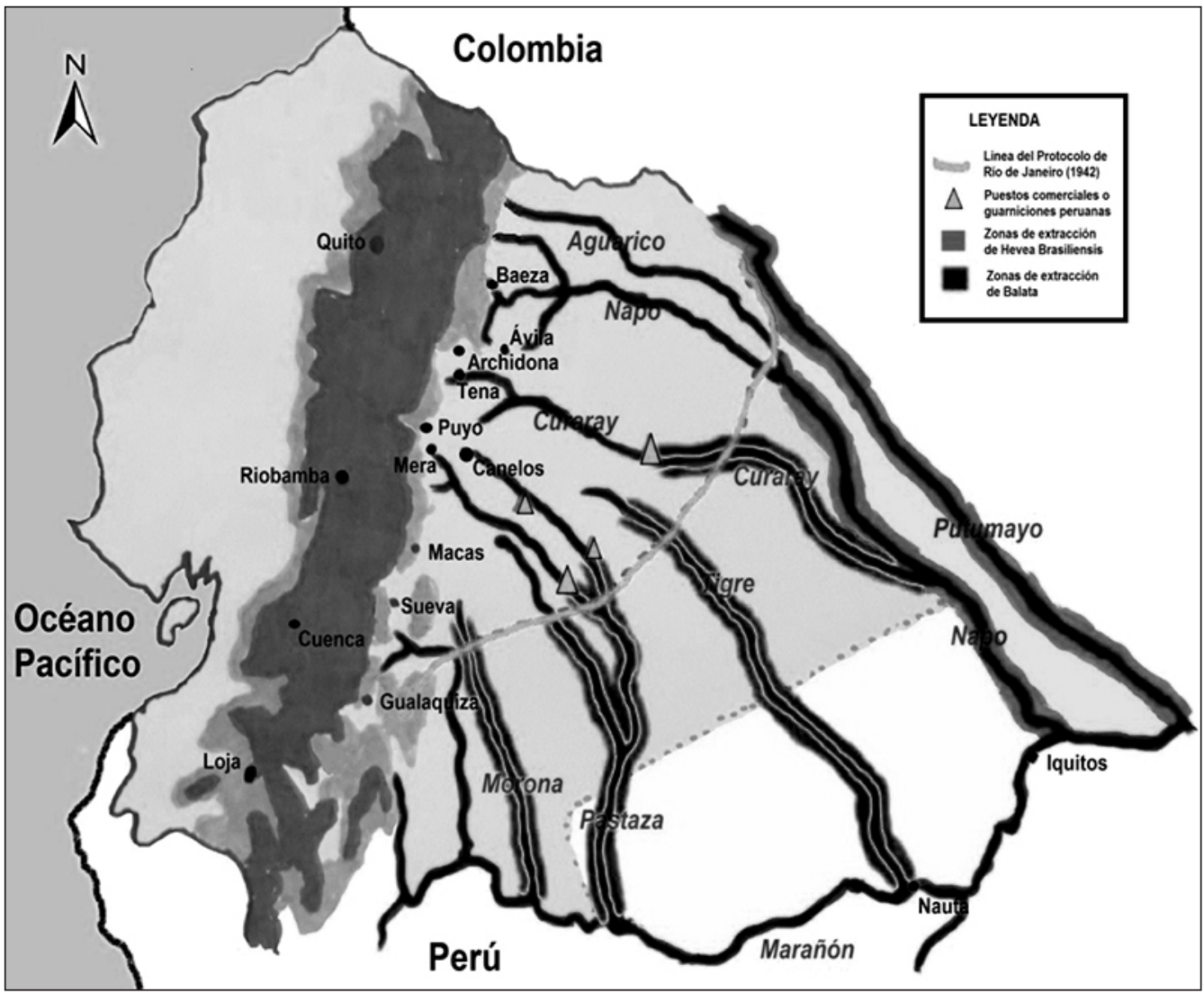

Figura 2. Fuente: elaboración propia a partir de Taylor (1994: 44)

indígenas para trabajar en haciendas caucheras a cambio de productos manufacturados como telas o herramientas (Muratorio, 1998: 181, 201). Además de la violencia directa, las poblaciones indígenas fueron también diezmadas por las numerosas epidemias que asolaron periódicamente la Amazonía (Ibid.: 178). En todo caso, ya sea por el esclavismo o ya sea por diferentes tipos de patronazgo (prebendas, sistemas de enganche, intercambio por productos manufacturados, etc.), esta época supuso la movilización de miles de indígenas de unas zonas a otras, "dando cuenta de la caleidoscópica configuración étnica de algunas de las áreas indígenas amazónicas" (Barclay, 1998: 128) y contribuyendo a la desaparición directa o debilitamiento extremo de muchas etnias, que eran finalmente absorbidas por la cultura quichua dominante, pues quichuanización y civilización eran sinónimos en esa época (Ibid.: 145) ${ }^{10}$.

En cuanto a la zona que nos ocupa, la cuenca baja del Curaray, el impacto de la actividad cauchera fue demoledor en la configuración étnica de la misma. Los záparas eran los más antiguos pobladores conocidos de esta región de la Amazonía ecuatoriana. Fueron numerosos los grupos de filiación zápara que habitaron el territorio comprendido entre el Napo y el Pastaza. Hemos sabido de ellas, primero, por las crónicas de misioneros y viajeros, y, más tarde, por

10 En efecto, los quichuas amazónicos son resultado de un complejo proceso de absorción de otros grupos por parte de la cultura quichua. Este proceso ha sido tratado por autores como: Whitten (1987: 25-30), Hudelson (1987), Udo Oberem (1980), Blanca Muratorio (1998: 71-76), y Miguel Ángel Cabodevilla, que profundiza en esta cuestión de manera más específica para la época del caucho (1999: 145-173). 
los informes de caucheros y autoridades políticas. En todos estos documentos hay numerosas referencias a etnias del conjunto záparo. Todas estas fuentes, y la memoria oral de algunos de los pocos supervivientes, coinciden en señalar una trayectoria que comienza en la existencia de un apogeo de esta cultura sobre un vasto territorio ocupado por una población muy segmentada, pasa por un momento en que sus contornos son desdibujados por las numerosas incursiones de misioneros, comerciantes, caucheros, etc., para acabar en una situación crítica y de aparente desaparición ${ }^{11}$. Así, ¿qué es lo que contribuyó a esta misteriosa desaparición de un pueblo otrora numeroso y poderoso? Eso es lo que veremos a continuación, pues la historia del río Curaray va ligada a la historia de este pueblo.

Como hemos explicado, los numerosos documentos de esta época parecen señalar que el inmenso territorio comprendido entre el Pastaza, el Corrientes, el Tigre y el Napo correspondía al conjunto tribal záparo. Dentro de este territorio, Jorge Trujillo describe un panorama donde todos estos grupos convivirían entre alianzas y guerras, ejerciendo mucha resistencia en un principio a la penetración misionera. El éxito logrado en su empeño mostraba a los ojos de los misioneros una organización formidable, hasta llegar a percibirlos como una unidad quasi militar e, impresionados por su número y firme oposición, postular la existencia de la "nación zápara" (Trujillo, 2001: 18). Así, en lo que es el Curaray, la actividad misionera no tuvo ni mucha intensidad ni mucho éxito, reduciéndose al establecimiento de una fundación en 1965, San Miguel, que apenas tuvo un par de años de vida (García, OCD, 1999: 145). Esta región permaneció, por tanto, como una "zona refugio" hasta mediados del siglo XIX (Cabodevilla, 1999). De esta manera los grupos záparas quedaron como una de las poblaciones más grandes sobrevivientes al primer frente misional. Y, como hemos dicho, desde la expulsión jesuítica hasta la época del caucho se vive un periodo de abandono de la región oriental por parte de la sociedad blanco-mestiza, no habiendo prácticamente rastro de contacto de colonos o misional alguno (Ibid.: 110). Resumiendo, el Curaray era a la llegada de los españoles el río de los záparas y continuó siéndolo hasta la aparición de los caucheros, tal y como lo corrobora Manuel Villavicencio en 1858 cuando habla de dicho río: "Este río i dichos afluentes son auríferos, i todos ellos habitados por diferentes tribus de Záparas, que llevan los nombres de los ríos cuyas cercanías habitan. (...) La navegacion de este rio es muy frecuentada por las tribus Záparas que se visitan continuamente unas á otras." (1958: 75-76)

La exploración cauchera comienza en el Curaray a finales del XIX, primero de una forma ambulante para finalmente acabar instalándose en sus riberas. Lo que había sido un río poco transitado, y en el que las misiones no habían tenido mucha capacidad de penetración, en poco tiempo se transforma radicalmente. Las lanchas de las casas comerciales de Iquitos surcan regularmente el Curaray surtiendo de mercancías a cambio de caucho, oro o productos agrícolas. Muchas haciendas se instalan a las orillas de este río, aunque muy pocas tienen la capacidad de durar un largo tiempo. La mayoría aparecen y desaparecen, se trasladan o cambian de dueños. Por eso es muy difícil poder realizar un seguimiento de todo este movimiento. En la figura 3 se puede observar la localización aproximada de un censo de haciendas de esta época en lo que es el río Curaray perteneciente hoy en día a Ecuador, que puede servir como muestra del dinamismo y de los intentos colonizadores que se hicieron.

Entre 1870 y 1920 el Curaray, junto con otros ríos como el Pastaza, Tigre y Napo, evolucionó hasta convertirse en una gran frontera económica (Gamarra, 1996: 58). Comerciantes ecuatorianos, peruanos, italianos, y compañías inglesas, francesas, italianas y peruanas invadieron en poco

11 Después de ser considerados extinguidos por numerosos antropólogos, a partir de finales de la década de los noventa, y quedando apenas 5 personas mayores conocedoras de la lengua zápara, comienza un proceso de zaparaización, de revitalización y reinvención de la cultura zápara. Proceso que finalmente sería reconocido por la UNESCO al declarar las manifestaciones orales záparas como Patrimonio Oral de la Humanidad en el 2001 (Bilhaut, 2011: 4041). Dentro de este proceso de etogénesis la población estrictamente de origen zapara en las comunidades de esta nacionalidad no es representativa, siendo la gran mayoría inmigrantes de origen shuar, achuar y quichua que se han incorporado a los asentamientos existentes en el transcurso de los últimos 15 años (Trujillo, 2001: 45). 


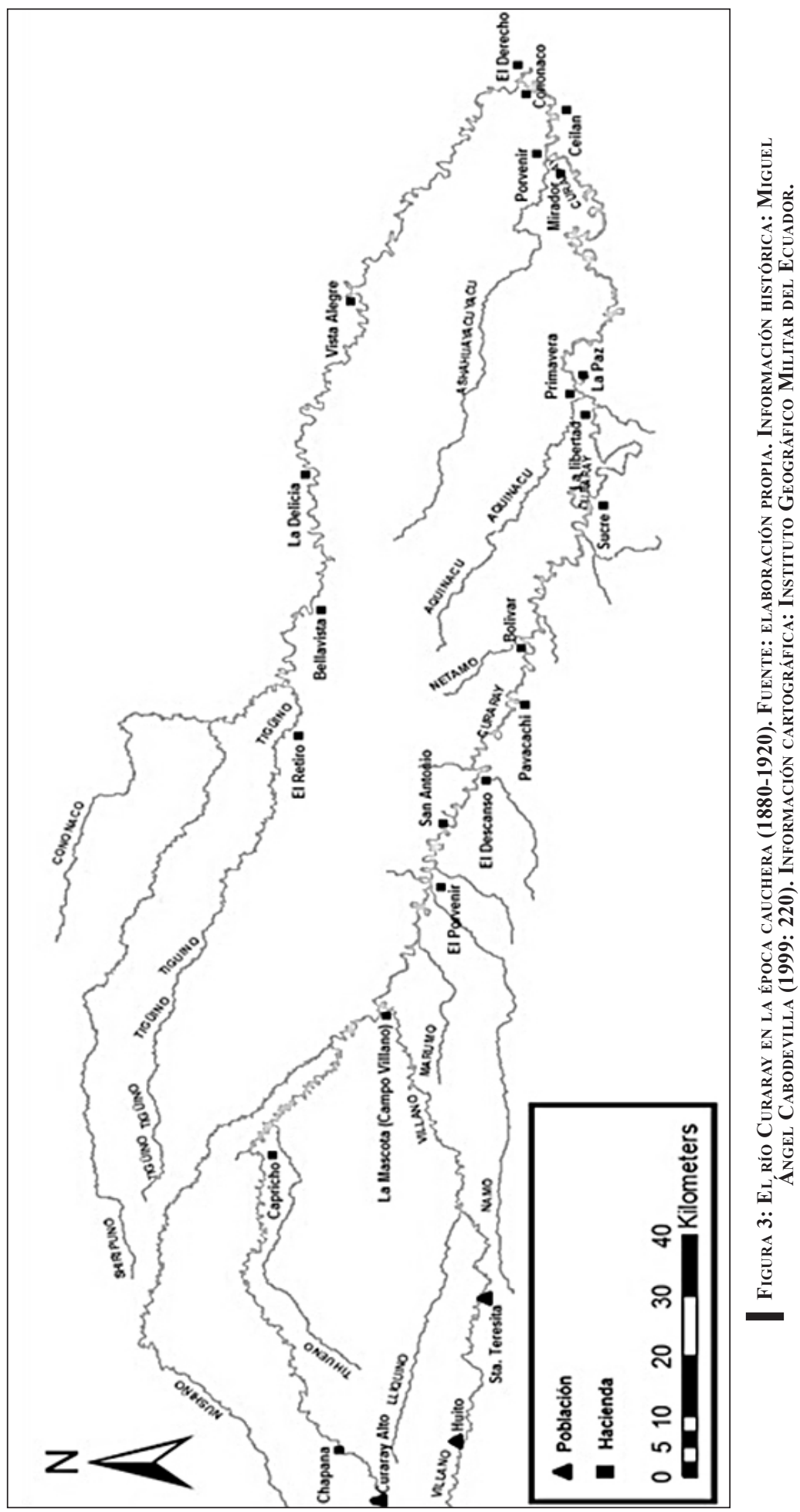


tiempo las orillas del Curaray (Bilhaut, 2011: 38, Cabodevilla, 1999: 220-232). En un primer momento los colonos caucheros comienzan a establecerse lentamente y utilizan como mano de obra a záparas residentes en las cabeceras del Curaray, los cuales estaban ya acostumbrados al trato con la sociedad blanco-mestiza (los jesuitas habían establecido una misión en la cabecera del Curaray y más tarde fue misionada por los dominicos), trabajando principalmente con los sistemas de patronazgo basados en el enganche por la deuda. La primera consecuencia del inicio de esta actividad sería la expulsión al interior de los grupos záparas que ocupaban estos márgenes y que no estaban por la labor del contacto. Pero, conforme la actividad se fue intensificando, la necesidad de mano de obra sería cada vez más acuciante por lo que recurrieron a peones traídos de la Sierra y, sobre todo, a runas del Napo (quichuas), pues la compra-venta de peones era una actividad muy común. Pero la mano de obra seguía siendo insuficiente y no tardó en ser cada vez más frecuente el uso de indígenas "cazados" en correrías. En efecto, numerosas etnias y grupos fueron expulsadas hacia el interior y los enfrentamientos con ellos eran bastante frecuentes en los largos recorridos que se hacían en busca de árboles de caucho. Otras veces directamente se hacían correrías para "limpiar" territorios que después serían explotados para la actividad. Muchos de los capturados en estos "encuentros" eran llevados a las haciendas y utilizados como peones. Para estas correrías, y para la captura y el control de peones huidos de las haciendas, los patrones utilizaban a los záparas (muchas veces actuando contra otros clanes záparas), muy hábiles para esta labor de rastreadores, valientes y, además, temidos por los runas (Cabodevilla, 1999: 142,151; Oberem, 1980: 114; Bilhaut, 2011: 37). Esto situó a los záparas en una mejor posición que otras etnias en el mundo de las haciendas, pero sobre todo "consiguieron el odio y enfrentamiento total entre la peonada india recolectora de caucho y los salvajes que defendían sus tierras invadidas" (Cabodevilla, 1999: 142), odio que más tarde se volvería en contra del propio pueblo záparo.

Este clima de violencia y las recurrentes epidemias, disminuyen drásticamente el número de záparas en todo su territorio, hasta el punto que para principios del siglo XX han desaparecido de muchas regiones, como el Napo (Ibid.: 152). Ya en los inicios de la actividad cauchera en el Curaray, en 1890, el padre Guerrero Sosa en uno de sus viajes afirma: "A orillas de este río existen muchos tambos y los pobres indios están diezmándose por el sarampión" (citado en: Cabodevilla, 1999: 154). En resumen, para 1920 ya no quedan záparas libres en el Curaray, la mayoría han sido "enganchados" para la actividad cauchera, otros muchos han huido internándose tierra adentro teniéndose que enfrentar, y siendo aniquilados la mayoría de las veces, a otras "tribus de salvajes aucas" que, como explicaremos, ya estaban implantándose por estos territorios. Los que quedaban estaban muy diezmados por las enfermedades y enfrentados entre ellos y con otros indígenas debido a las dinámicas potenciadas por los caucheros.

Por tanto, el escenario que dejó a su paso la explotación cauchera fue desolador, sobre todo para los záparas. La dispersión de sus poblaciones, la disminución drástica de las mismas, un entorno de violencia generalizada y odios (sobre todo contra ellos), un mundo quichua-hablante en expansión que los envolvía, un proceso de adopción del quichua muy avanzado (aunque todavía hasta mediados de siglo el bilingüismo era muy generalizado en estas poblaciones [Bilhaut 2011: 39]), y un sistema de alianzas interétnicas en progresión, conducirán a un proceso de quichuanización (Reeve, 2002: 87), a una disolución de la identidad zápara en el mundo quichua dominante que haría a este grupo invisible, como lo describe Anne-Gaël Bilhaut:

"Los záparas dicen que entre 1970 y 1990, optaron deliberadamente por dejar pensar que eran kichwas. De esta manera, ellos estimaban que los enemigos tradicionales se olvidarían de ellos. La identidad zápara ya no era una categoría-refugio, no tenían razones para distinguirse de las grandes categorías indígenas regionales. Al adoptar una identidad kichwa, se favorecían con los progresos del movimiento político, tanto más en cuanto estaban afiliados a la principal organización kichwa" (OPIP) (2011: 61). 
Pero durante todo este período de pérdida paulatina de la hegemonía zápara en estos territorios, se estaba dando paralelamente otro proceso inverso. Un pequeño pueblo, que muy probablemente se había mantenido aislado durante mucho tiempo en algún lugar remoto entre el Napo y el Curaray (su idioma totalmente diferente y sin cesiones de otras lenguas vecinas así lo demuestra), comenzaba a ganar terreno en la margen izquierda del Curaray. En efecto, los huaorani, seguramente arrinconados por otros pueblos más poderosos desde el norte (Napo) y los záparas desde el sur habrían permanecido, durante mucho tiempo, "escondidos" y protegidos de la penetración blanco-mestiza en lugares muy inaccesibles entre los ríos Napo y Curaray. Posiblemente debido a la presión ejercida desde el norte por los grupos expulsados hacia el interior de las riberas del Napo tras la llegada de los españoles y a que en el sur la población zápara del Curaray se habría mermado considerablemente debido a las enfermedades por el contacto con la sociedad blanco-mestiza y a la violencia interétnica, los huaorani se fueron poco a poco desplazando hacia este territorio y ocupando las riberas del Curaray hasta sus cabeceras (Cabodevilla, 2009). Aunque desconozcamos la cronología exacta de la llegada al Curaray de los huaorani, lo que parece claro es que durante los siglos XVIII y XIX esta etnia se expandió por toda la margen izquierda del Curaray (Cabodevilla, 1999: 162-163). Y con el impacto de la actividad cauchera sobre las poblaciones locales, el río Curaray quedó a partir de 1930 prácticamente despoblado de otros que no fueran esos "aucas" (Reeve, 2002: 15).

La crisis del caucho trajo consigo la disolución del mundo de las haciendas que había ido vinculada a esta actividad. Rápidamente desaparece el entramado de haciendas y las pocas que quedan en la década de 1920 tienen poca capacidad de ejercer un control efectivo sobre el mundo indígena (Muratorio, 1998: 258). A partir de entonces se irá produciendo una lenta, pero progresiva, desaparición de los patronazgos y liberación de los runas (indígenas ya quichuanizados) que empiezan a ocupar algunos lugares del Curaray, sobre todo en su tramo alto. Esta tendencia se ve interrumpida por las epidemias que acaban despoblando prácticamente el Curaray en la década de los treinta. Sólo un pequeño poblado situado en la cabecera del Curaray, fundado por los jesuitas en su segunda aventura ${ }^{12}$ y atendido por los dominicos desde 1898, sigue persistiendo a la desaparición del mundo del caucho y las epidemias. En 1927 el pueblo es trasladado al río Villano tanto por razones administrativas (para estar dentro de los límites de la misión dominica) como por los ataques de los huaoranis que cada vez se hacían más frecuentes. Este pueblecito sobrevive como puede a las epidemias y empieza a crecer a mediados de la década de los treinta. Hasta tal punto que una crónica de 1938 relata que el Gobierno se plantea utilizar este pueblo como un núcleo colonizador a partir del cual fundar una red de poblaciones en el Villano y el Curaray. Ese año el pueblo está compuesto de 142 habitantes (Cabodevilla, 1999: 227).

En 1941 se producirá, como veremos, el conflicto con el Perú, la fijación de la frontera en el Protocolo Río de 1942 y el cierre de la misma. Lo poco que podía quedar en la parte baja del Curaray (y que sobrevivía vinculado a Iquitos) desaparece totalmente. Esta zona queda aparentemente despoblada, como nos confirma un viejo comunero de Lorocachi, Camilo Alvarado, que bajó a finales de la década de los setenta a construir la pista de aterrizaje de Lorocachi: "Aquí particulares no había, solamente vivíamos en Curaray, de ahí bajamos poco a poco para vivir acá ya para siempre."13. En resumen, la cuenca del Curaray queda totalmente deshabitada (a excepción de los huaorani) a partir de esta fecha, prácticamente aislada del país y del resto del mundo por el cierre de la frontera con Perú. Forma parte de esa amazonía que, por sus ríos navegables, había mirado históricamente hacia el este, se había vinculado al mundo vía explotación cauchera, y que ahora quedará prácticamente aislada. Excepcionalmente los núcleos

12 En 1861 el conservador Gabriel García Moreno alcanza la presidencia del país e intenta impulsar un proyecto de organización del Estado, donde la incorporación del Oriente se consideraba un punto esencial. Pero, reflejo de la incapacidad e impotencia estatal, este proyecto vino vinculado nuevamente a las misiones católicas. Es el momento en el que los jesuitas vuelven otra vez, llamados por García Moreno, a la Amazonía ecuatoriana (Esvertit, 2008: 15-110).

13 Entrevista realizada el 14/08/2009. 
poblacionales de las cabeceras siguen sobreviviendo vinculados a las misiones de los dominicos y de los josefinos que se hicieron cargo de la antigua misión de Curaray (ahora con el nombre de San José) a partir de los sesenta (Reeve, 2002: 16). Estos núcleos poblacionales son ya de runas, es decir, quichua-hablantes, aunque en su seno se oculte una sociedad multiétnica constituida por individuos procedentes de distintos grupos étnicos como los záparos, canelos, achuar y quichua del Napo (Ibid.: 9).

\section{El desarrollismo estatal}

En 1941, el clima de fuerte tensión entre Ecuador y Perú acabó en un conflicto armado ${ }^{14}$. Nuestra hipótesis es que este conflicto acabó con una disputa territorial antigua, sancionando finalmente en un documento legal una redefinición de fronteras que habían quedado sin fijar de manera oficial desde el inicio de los estados nación sudamericanos en el siglo XIX, pero que se habían ido estableciendo de facto por el proceso de ocupación efectiva del territorio por parte de Perú y que se acabaron de conformar en la época del caucho. El 29 de enero de 1942 se firmó en la ciudad brasileña de Río de Janeiro el Protocolo de Paz, Amistad y Límites. Ecuador perdió en este acuerdo, según el discurso oficial que se ha incrustado en la genética nacional, la mitad de su territorio, quedando fijada la frontera más o menos hasta donde llegaba con más intensidad la actividad cauchera y Perú ejercía un control real del mismo. Hay que remarcar que hubo un hecho que para muchos autores tuvo una importancia considerable en el incremento de las tensiones que desembocaron en el conflicto bélico. En las décadas anteriores habían comenzado los contratos exploratorios con compañías petroleras. Como señala JeanPaul Deler, este conflicto tuvo un "fuerte olor a petróleo", pues las concesiones exploratorias realizadas por Ecuador a una compañía anglo-neerlandesa, la Royal Dutch Shell, se superponían con los territorios concesionados por Perú a una compañía norteamericana, la Stardard Oil of New Jersey (Deler, 2007: 160).

Aunque a nivel simbólico este hecho dejó una herida abierta que año tras año reafirmaba la "ecuatorianidad" en base a este conflicto en multitud de ritos patrióticos (Radcliffe 1998), existieron otros efectos políticos y económicos de carácter mucho más práctico. Por un lado el Estado ecuatoriano ya sabía a qué limites atenerse, pudiendo concentrar sus limitados esfuerzos en definir una estrategia geopolítica concreta para la ocupación real del territorio. Y por otro lado, la seguridad jurídica que le otorgaba a las compañías internacionales una definición clara de los límites, permitió que, una vez acabado el conflicto de la II Guerra Mundial y con la economía internacional en crecimiento, pudieran regresar en la década de 1950 las compañías petroleras, que habían abandonado su actividad tras el conflicto, y esta vez venían para quedarse. Fue entonces cuando llegaron las actividades vinculadas a la explotación petrolera: vías de comunicación, mano de obra asalariada, desbroces masivos, etc. Esta zona se convirtió en la principal fuente de divisas del país, sufriendo un cambio acelerado e irreversible a partir del inicio de la extracción petrolera de la Amazonía ecuatoriana en agosto de 1972 (Acosta-Solís, 1992: 80). La situación de esta región cambió drásticamente, pasando del mítico Oriente a la Región Amazónica Ecuatoriana (RAE) ${ }^{15}$.

Pero hubo regiones, como la que nos atañe, que por su lejanía e incomunicación tuvieron mucha más dificultad de ser integradas al espacio nacional. La Royal Dutch Shell pasó en los años cuarenta por esta región, construyendo varias bases a lo largo del río y una pista de aterrizaje en Campo Villano, en la cabecera (ver figura 3). El Ejército se estableció en 1943 alrededor de la

14 Para una buena síntesis de los conflictos fronterizos entre Ecuador y Perú desde los inicios de las repúblicas hasta la firma del Tratado de Paz definitivo en 1998, y focalizando en la Guerra de 1941 y el Protocolo de Río al que dio lugar, consúltese John Ronald Bruce (1999). Para un buen análisis de cómo se vivió la Guerra de 1941 en cada uno de los dos países, en especial en Ecuador, y sus consecuencias reales y simbólicas, consúltese Hernán Ibarra (1999).

15 La Cámara Nacional de Representantes del Ecuador, mediante el Registro Oficial 245 publicado el 5 de agosto de 1980, cambió la denominación de Región 'Oriental' por el de Región ‘Amazónica'. 


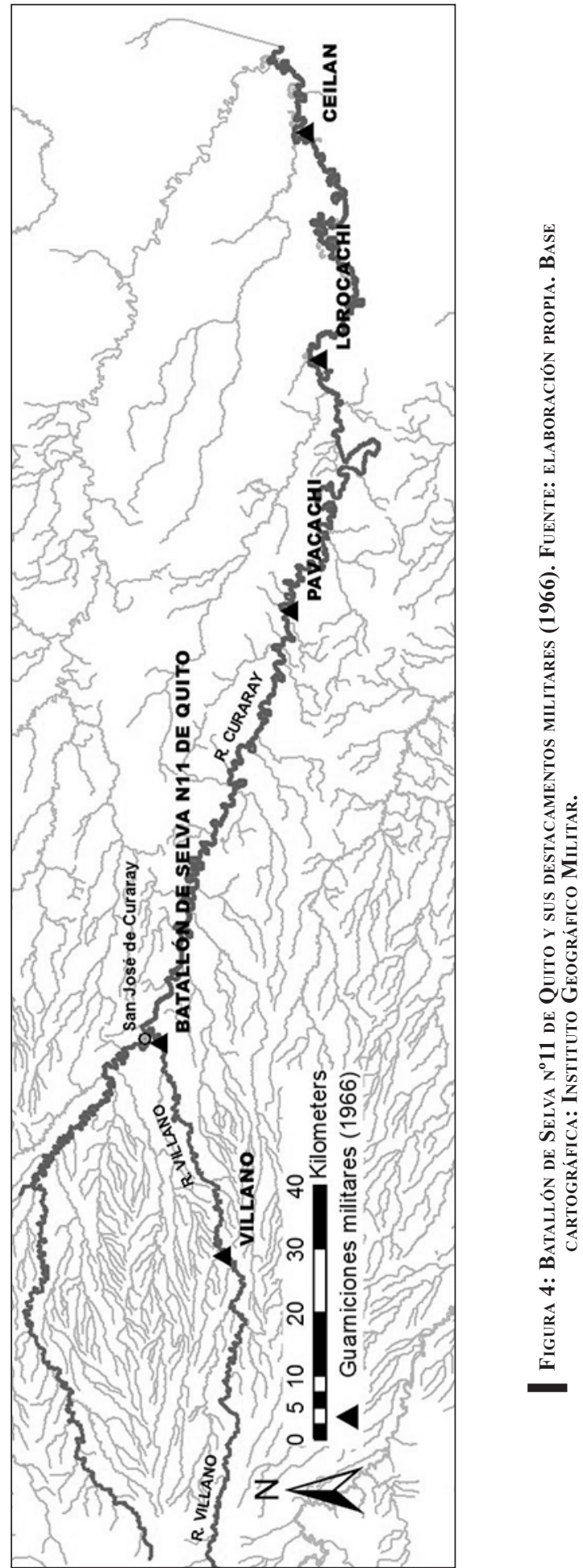


base que la Shell había construido en Villano. Y en 1952 algunos indígenas quichua-hablantes de la cabecera del Villano, que habían permanecido alejados del Curaray por miedo a los huaoranis y por la labor de la misión dominica, bajaron a establecerse al lado de los militares en Villano, escapando de la escasez de caza y pesca en su zona (Dall'Alba, 1992: 415). Comenzaba, como veremos, la "reconquista" del Curaray en manos de los militares y los quichuas. Los militares jugarían un papel preponderante en esta nueva etapa por dos factores principales. Por un lado el Estado ecuatoriano era débil por lo que su presencia en forma de administración civil es estos lugares era prácticamente inexistente, dejando al Ejército como representante único del mismo. Por otro lado, en la nueva política de seguridad nacional tras la Guerra de 1941, y con las fronteras ya fijadas por el Protocolo de Río, a los militares se les asigno un papel muy importante en la protección de las fronteras recién creadas del Oriente. Para muchas comunidades indígenas internadas en regiones aisladas y distantes como la del Curaray, las guarniciones militares se han convertido durante mucho tiempo en el único enlace con el Estado y el resto de la sociedad ecuatoriana, estableciendo un tipo de simbiosis muy particular. Muchos de estos asentamientos militares en territorios estratégicos de la geografía amazónica, se han convertido en puntos referenciales alrededor de los cuales se han establecido comunidades indígenas, pues ofrecían posibilidades de comercio, transporte aéreo y acceso a servicios básicos, convirtiéndose así en poderosos polos de colonización (Báez, 2004: 196-197).

Puntos de colonización que adquirieron un nuevo matiz a partir de los sesenta con la ideología desarrollista ${ }^{16}$ de la época. Esta nueva filosofía se sustenta en una metáfora, la del Estado como un organismo en el que el subdesarrollo, la degeneración y la decadencia pueden ser su peor enemigo. Es entonces cuando se potencia con más fuerza que nunca la ideología desarrollista en los regímenes militares que gobiernan Ecuador en las décadas de los sesenta y los setenta, pues el Estado es un organismo que necesita del desarrollo interno para evitar su desintegración. La metáfora orgánica sitúa, además, en un lugar muy destacado el fortalecimiento de la frontera para la supervivencia del organismo estatal ante las amenazas externas peruanas (Ortiz Batallas, 2006: 41). La colonización de estas áreas de frontera se convierte en una prioridad para la seguridad nacional. Es lo que llamaron "fronteras vivas", barreras humanas, que tenían como objetivo asentar población para lograr la posesión efectiva de estos territorios y al mismo tiempo lograr fortalecer el sentimiento de pertenencia nacional de amplios sectores poblacionales donde éste era muy débil debido a la histórica escasa presencia del Estado ecuatoriano.

En 1958 el destacamento inicial instalado en Campo Villano se transforma en batallón ${ }^{17}$ formado por unas 200 personas. Esto convierte a la zona de confluencia entre el Villano y el Curaray en un atractivo lugar para muchos indígenas. En 1960 el batallón se traslada ya a las orillas del Curaray (Dall'Alba, 1992: 415-417). Son los años en el que el desarrollismo comienza a despegar en Ecuador y se recupera la vieja idea de la recolonización de la cuenca del Curaray, enmarcado dentro de la política de seguridad nacional de las fronteras vivas. El núcleo poblacional inicial se ve reforzado por la llegada de indígenas de otras poblaciones alejadas, atraídos por las posibilidades de trabajo que el batallón y la compañía petrolera ${ }^{18}$ ofrecían. Muchos de ellos acabarían quedándose y trayendo a sus familias (Ibid.: 417). Una vez establecido el batallón en

16 Este periodo, desde la posguerra de la II Guerra Mundial hasta los ochenta, se conoce como la época del desarrollismo clásico. Se caracteriza por el intento de la construcción de aparatos estatales fuertes con capacidad de intervención, pues se consideraba que el Estado debía jugar la función de agente modernizador. Es la época del paradigma estructuralista, de los planes de industrialización y de las reformas agrarias. Su momento dorado fue la década de los sesenta, con la llegada de gobiernos progresistas y el lanzamiento por parte de EEUU de su Alianza para el Progreso. Este periodo acaba en los ochenta con la llegada del neoliberalismo y los planes de ajuste estructural (Bretón, 2009).

17 Los destacamentos son pequeñas guarniciones militares que dependen de una base central, que es el batallón. Desconocemos el tamaño de este primer destacamento antes de transformarse en batallón, pero sabemos que los destacamentos dependientes del nuevo batallón desde entonces hasta a la actualidad han estado formados por no más de 10 personas que se turnaban por días. Un destacamento vendría a ser un puesto avanzado de vigilancia.

18 La Western Geophisical se instaló en 1974 en esta región para la realización de prospecciones geológicas. 
San José de Curaray se creó el destacamento de Lorocachi, y en en junio de 1974 el Batallón puede por fin trasladarse definitivamente a Lorocachi.

A partir de entonces, poco a poco se fueron estableciendo en Lorocachi familias en los alrededores del Batallón, tanto de trabajadores militares y civiles del mismo, como familias indígenas atraídas por las oportunidades que los militares y el nuevo territorio ofrecían. En 1985 el coronel Marco Miño ${ }^{19}$, encargado del batallón militar de Lorocachi en aquel entonces, organiza a los civiles que vivían alrededor del batallón militar y les otorga oficialmente, con la ayuda del Instituto Ecuatoriano de Reforma Agraria y Colonización (IERAC), unos lotes de terreno. Se puede considerar estos momentos el nacimiento oficial de la comunidad de Lorocachi. Y una vez organizada, había que "desarrollar" a la población civil, labor para la cual llegó el 18 de septiembre de 1985 una comisión del Instituto Nacional de Colonización de la Región Amazónica Ecuatoriana (INCRAE) ${ }^{20}$. Esta visita formaba parte de un viejo plan del INCRAE y los militares: el Proyecto de Desarrollo Rural Integral en Fajas de Frontera (DRIF). Finalmente, y con un préstamo del Banco Interamericano de Desarrollo (BID) el DRIF fue diseñado. Para Lorocachi el proyecto estimaba un gasto de 1.154.695 USD tanto en infraestructura como en asistencia técnica y procesos de legalización de tierras. La intención era que a partir de un núcleo poblacional grande y estable en Lorocachi se pudiera establecer una red de poblaciones a lo largo del cauce del Curaray (DRIF 1990). Este proyecto, el cual su diseño finalizó en 1990, nunca se ejecutó, pues para esas fechas el Estado ya estaba muy debilitado y con muy poca capacidad de acción por la crisis de la deuda y los planes de ajuste estructural (Martínez-Sastre, 2014: 213231).

\section{Plataformas étnicas y territorio}

Ecuador entró en la década de los noventa conmocionado por el primer gran levantamiento indígena contemporáneo. A partir del 3 de junio de 1990 y por alrededor de nueve días, miles de indígenas ocuparon las carreteras de la Sierra y las principales ciudades hasta llegar a la capital, Quito, y tras ocho días de protestas obligaron al presidente Rodrigo Borja a sentarse a negociar los 16 puntos del Mandato por la vida de la Confederación de Nacionalidades Indígenas del Ecuador (CONAIE) y, principalmente, la resolución de conflictos por la tierra estancados (Barrera, 2001: 113 - 153). Así es como irrumpió con fuerza en el panorama nacional la CONAIE, que había sido fundada en 1986. Esta irrupción y su posterior consolidación a lo largo de los noventa situaron al movimiento indígena como un potente e importante actor social en el panorama político ecuatoriano, tendencia que ha sido constatada también en otros países latinoamericanos con una fuerte presencia de población indígeno - campesina ${ }^{21}$. La irrupción del movimiento indígena posicionaría la "cuestión étnica" como una de las principales prioridades de la agenda de las agencias de cooperación y de los poderes públicos.

19 Toda la información de la historia del batallón militar está extraída de los Libros de Relatoría del mismo batallón que van desde el 1966 hasta el 2001. Dichos libros fueron encontrados en la biblioteca del batallón de Lorocachi.

20 El INCRAE fue una institución creada por la Ley de Colonización de la Región Amazónica Ecuatoriana expedida mediante el Decreto Supremo No. 2092, publicado en el Registro Oficial 504 del 12 de enero de 1978. El objetivo de este instituto era el "vincular la región amazónica al resto del país a través de un proceso de desarrollo integral, con un énfasis en las zonas fronterizas" (Tamariz y Villaverde, 1997: 85). Su función era ir un paso más allá de los programas de colonización del Instituto Ecuatoriano de Reforma Agraria y Colonización (IERAC), pues las especificidades de la región amazónica habían mostrado las limitaciones de los mismos sobre todo en las zonas más alejadas, y funcionar como un organismo de diseño, coordinación y ejecución de proyectos y programas de desarrollo y colonización en esta región (Andrade, 2004: 35).

21 El levantamiento indígena de Ecuador en 1990, la Marcha por la Dignidad y el Territorio de los pueblos del Oriente boliviano, en 1993, y la aparición en Chiapas del ejército Zapatista de Liberación Nacional, EZLN, en enero de 1994; fueron hechos decisivos para situar a los movimientos políticos indígenas como nuevos actores y sujetos en el escenario político latinoamericano, desde México hasta Bolivia. Sobre el tema de la politización de la etnicidad en América Latina véase, entre otros: Rodrigo Montoya (2008), José Bengoa (2000), Nancy Grey Postero (2007), Donna Lee Van Cott (2007) y Deborah Yashar (2005). 
Este proceso descrito de consolidación del movimiento indígena a principios de los noventa, se dio en un principio en la Sierra, aunque muy pronto organizaciones indígenas de otras regiones, como la Organización de Pueblos Indígenas de Pastaza (OPIP), adquirieron, como veremos, una fuerte notoriedad. Así como en la Sierra la lucha principal había sido por la tierra, en la Amazonía su principal reivindicación y lucha sería por los territorios. La adquisición de personería jurídica por parte de comunidades y organizaciones indígenas permitía reclamar al Estado el título de propiedad comunal de la tierra, y en la primera convención de comunidades indígenas de la provincia de Pastaza en diciembre de 1979, se constituyó la Federación de Centros Indígenas de Pastaza (FECIP), que sería cambiado por el de Organización de Pueblos Indígenas de Pastaza (OPIP) en el segundo congreso realizado en octubre de 1981, para ser reconocida por el Estado en 1982 (Maldonado, 1988). En este primer momento la OPIP, aunque creada y dirigida mayoritariamente por quichuas, englobaba a otras nacionalidades de Pastaza (shiwiar, achuar y záparos), pero en la década de los noventa cada pueblo tomaría su camino y la OPIP quedó como la organización de los quichuas.

La propuesta de la OPIP se basaba en sus inicios en la defensa del territorio y la revisión de algunos instrumentos legales vigentes como la Ley de Colonización, argumentando que entraban en contradicción con los derechos consagrados a los pueblos indígenas en la legislación internacional. Así, a principios de los noventa el gobierno de Rodrigo Borja estableció negociaciones con las organizaciones indígenas y creó una Comisión de Asuntos Indígenas dentro del Gobierno para promover el diálogo (Criollo, 2007: 32-35). Pero en abril de 1992, ante el escaso avance de las negociaciones por la legalización de territorios, la OPIP organizó una marcha y el 23 de abril de 1992 llegaron hasta Quito 2.000 indígenas que se concentraron en el parque de El Ejido ${ }^{22}$. Esta marcha fue la culminación de una serie de movilizaciones que llevaron al gobierno Rodrigo Borja, sumido en una fuerte crisis económica y política, y sensibilizado con el alzamiento de 1990, a entregar títulos de propiedad a las comunidades indígenas de la Amazonía con una extensión de 1.159.525 hectáreas (Barrera, 2001: 124-126) ${ }^{23}$.

Por otro lado, las políticas de ajuste estructural supusieron un enorme replegamiento del Estado y una gran erosión de la capacidad interventora del mismo. Tendencia que favoreció la aparición de agencias de desarrollo de todo tipo, muchas de ellas ONG, que suponían una privatización de facto de las políticas de desarrollo en el medio rural. Externalización que vino acompañada de gran cantidad paradigmas y modas diferentes en cuanto a los proyectos de desarrollo se refiere ${ }^{24}$. Organizaciones indígenas y agencias de desarrollo serán, pues, dos actores imprescindibles para entender el devenir de muchas zonas de la Amazonia como la que nos atañe. En esta nueva coyuntura, así como en la Sierra habían sido las Organizaciones de Segundo Grado (OSG) las encargadas de desempeñar un rol importante como interlocutoras con el aparato de desarrollo (Bretón, 2012: 277), en la Amazonía, por el menor desarrollo de éstas (casi inexistentes para aquel entonces) y las características geográficas de la región, fueron las Organizaciones de Tercer Grado como la OPIP las interlocutoras válidas de las

22 Para un análisis en profundidad sobre esta marcha, su organización, evolución y consecuencias consúltese el interesante libro de Susana Sawyer (2004).

23 Es importante aclarar que esta titularidad se da sólo en territorios donde los indígenas demuestren una ocupación efectiva del mismo y que exclusivamente otorga derecho al usufructo del suelo y de lo que él se genere. El Estado es siempre el dueño único del subsuelo.

24 Este proceso de externalización y fragmentación de la actuación sobre la población fuera del paraguas del Estado ha sido conceptualizado, desde una perspectiva foucaultiana, como "gobernabilidad neoliberal". Se trata de la consolidación de formas de ejercer el poder a escala planetaria al margen de los estados por medio de relaciones sociales, ideologías e instituciones transnacionales (Gupta y Sharma, 2006: 277). En relación con Ecuador y el devenir del movimiento indígena, consúltese a este respecto el trabajo de Fernando Larrea (2010). Este proceso de fragmentación de la acción y de los paradigmas viene acompañado de un proyecto cultural neoliberal en lo que a las cuestiones identitarias se refiere, el multiculturalismo neoliberal. Para este tema, en América Latina, consúltese, entre otros: Carmen Martínez Novo (2006), Charles Hale (2002, 2004), Héctor Díaz-Polanco (2006), Víctor Bretón (2009) y Willem Assies (2000). 
ONG y de los demás organismos nacionales e internacionales ${ }^{25}$. La relación que se estableció entre estas organizaciones y las ONG resultaría compleja y controvertida, sobre todo en lo que se refiere a la confusión recurrente entre organización indígena y ONG. Esto condujo a que muchas organizaciones de base las percibieran como instituciones de servicios, posibilitando además la proliferación de unas burocracias indígenas con tendencia a perpetuarse en dichas organizaciones, reforzando la sensación de que las organizaciones se parecían más a ONG que a una verdadera federación de comunidades (Bebbington y Carroll, 2000: 31). La OPIP, desde luego, no se libraría de esta dinámica:

"Con la OPIP casi no hemos tenido mucho contacto, no ha habido ninguna relación pues, como le decía, ellos han trabajado así por su propia cuenta como se dice, no se han preocupado en apoyar acá, entonces no sé cómo serían más antes, como sabrían trabajar, pues se metían los antiguos líderes, más se metían a la corrupción pues" (entrevista Pastor Inmunda, comunero de Lorocachi, agosto de 2009).

La lucha por el territorio fue, en cierta manera, causa y consecuencia del nacimiento de la OPIP. A la vez la OPIP representó en el inicio de los noventa la estrategia más efectiva, sobre todo con la marcha de 1992, para acceder a grandes extensiones de territorio, así como para captar recursos de las agencias de desarrollo.

\section{Organización indígena y liderazgo}

Las dirigencias de más nivel en Pastaza han procedido históricamente de Sarayacu ${ }^{26}$. Así, dos importantes familias procedentes de esta comunidad se encuentran en el embrión de la organización indígena en Pastaza y se han disputado tradicionalmente el poder: los Villamil y los Viteri Gualinga, unidos por lazos consanguíneos. La ascendencia de los Viteri en Sarayacu se remonta a su abuelo, comerciante que llegó a esa comunidad como teniente político y contrajo matrimonio con una indígena. De ese matrimonio nació Aníbal Viteri, comerciante también, que se casó con Rebeca Gualinga.

La importancia de la familia Viteri Gualinga radica en su histórico papel como mediadora entre dos mundos, el indígena y el mestizo. Los comerciantes, y más tarde los patrones caucheros, se convirtieron ya desde el siglo XIX en intermediaros culturales entre el mundo blanco-mestizo y el indígena (Taylor, 1994: 58). En esa cadena de intervención, en el siguiente eslabón aparecían los indígenas quichuanizados, que eran, y siguen siendo en gran medida, algunos de los quichua amazónicos actuales, "los únicos que pueden traducir en términos indígenas las relaciones de fuerza entre indios y blancos, lo que les permite mantener el rol de intermediarios culturales esenciales" (Ibid: 60). Además, con el tiempo, esos dos eslabones, como hemos visto en el caso de Sarayacu, se fueron fusionando, dando lugar a unas familias, como la Viteri Gualinga, muy bien posicionadas para seguir ejerciendo ese rol de mediación (Reeve, 2002: 194). No es de extrañar, por tanto, que cuando en la década de los setenta comienza la lucha por la defensa de los territorios, familias como ésta se convierta en los mejores intermediarios con el Estado y la sociedad mestiza, posicionándose y consolidándose como una élite que asumió un papel fundamental, no sólo en su liderazgo, sino en la propia resignificación étnica y génesis de los discursos que hicieron posible esa notoriedad de la OPIP tanto a nivel nacional como internacional.

25 Una Organización de Segundo Grado (OSG) es una federación de comunidades. En el siguiente peldaño nos encontraríamos a las Organizaciones de Tercer Grado como una agrupación de OSG normalmente a escala provincial en Ecuador.

26 Sarayacu es una de las comunidades indígenas con mayor recorrido histórico de Pastaza. A partir de los ochenta mantuvo una oposición muy fuerte a la explotación petrolera y comenzó una larga disputa contra el Estado y la compañía petrolera Arco (Villamil, 1995). En los noventa esta lucha alcanzó repercusión internacional debido a la creación de toda una red de apoyo de organizaciones ambientales y de defensa de los pueblos indígenas (De Castro, 2009). Hasta la actualidad siguen siendo manteniendo una firme oposición a la actividad extractiva. 


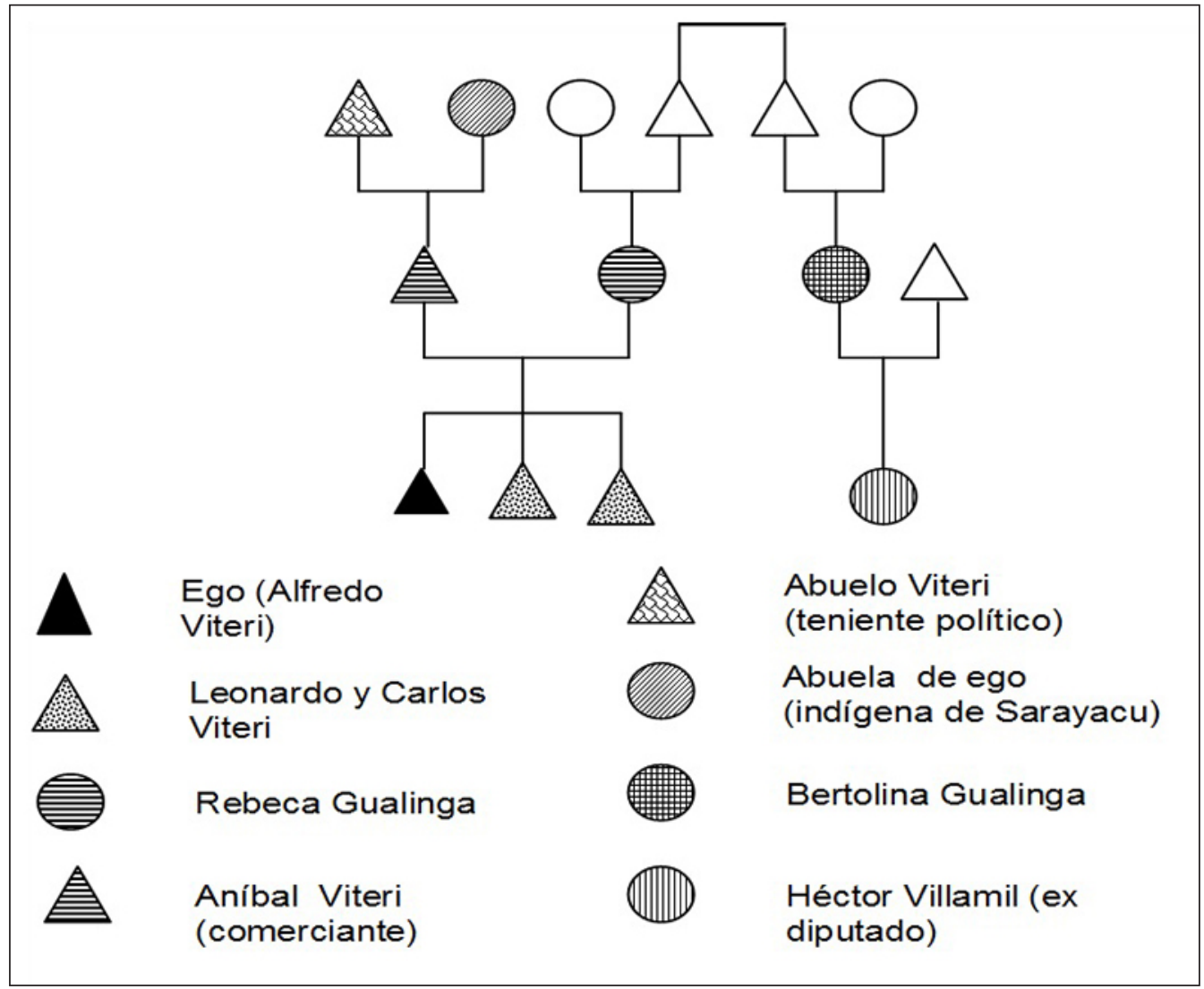

Figura 5: Familias Viteri-Gualinga y Villamil elaboración propia.

Los hermanos Alfredo y Leonardo Viteri son miembros fundadores de la OPIP, y ocuparon un rol muy protagónico en sus inicios y en la marcha de 1992. Alfredo Viteri es fundador y director durante muchos años de la ONG Instituto Quíchua de Biotecnología Sacha Supay (IQBSS), ONG indígena amazónica que canalizó gran cantidad de recursos económicos, y en el 2012 era el coordinador general del Consejo Quichua de Pastaza, entidad que sustituyó en 2010 a la OPIP. Por su parte, Leonardo Viteri fue creador y director del Instituto Amazanga y director técnico del Instituto de Ecodesarrollo de la Región Amazónica Ecuatoriana (ECORAE) ${ }^{27}$ en Pastaza en 2005-2006. Por último, Carlos Viteri fue de 2002 a 2009 funcionario en Washington del Banco Interamericano de Desarrollo (BID) como especialista en pueblos indígenas para América Latina y el Caribe, del 2009 a 2012 ocupó el cargo de Secretario Ejecutivo del ECORAE y en 2012 entró al parlamento como diputado amazónico. El tronco Viteri-Gualinga conforma una suerte de mediadores con el establishment. Como ha puesto de manifiesto Mónica Martínez (2007) en un trabajo sobre los kuna de Panamá, este tipo de mediadores indígenas tienen un papel muy importante en la traducción de las demandas de sus pueblos a un lenguaje entendible por el aparato del desarrollo. Son ellos, y no al revés, los que se adaptan al discurso oficial que

27 El ECORAE fue creado en 1992 por el Estado ecuatoriano con el fin de hacer frente a las necesidades de la población amazónica, que recordemos estaba en un duro proceso de demanda de derechos como el territorio, y a la misma vez mitigar las críticas internacionales de su accionar en la Amazonía en un momento de auge del discurso ambientalista. Para una mayor profundización del papel del ECORAE en la Amazonía ecuatoriana consúltese el trabajo de Karen Andrade (2004). 
se articula desde las más altas esferas del aparato del desarrollo (con el BM y Naciones Unidas a la cabeza) y que se articula alrededor de la ecologización y etnificación de las demandas indígenas.

\title{
La oenegización de la estrategia territorial
}

Así, en 1992 lograron la legalización de más de un millón de hectáreas, pero en estos territorios legalizados no se encontraba la zona fronteriza de la cuenca baja del Curaray, pues la OPIP, por un lado no logró demostrar, como el Estado le reclamaba, su ocupación efectiva, y por otro, el Ejército reivindicaba parte de ella como integrante de una franja de seguridad. Parte de la estrategia de los líderes indígenas consistió en, no sólo reivindicar los territorios, sino situarse de la forma más ventajosa para la negociación:

\begin{abstract}
"Asumimos esa estrategia porque en la zona fronteriza, en la cuenca baja del río Curaray particularmente, y en la parte de la cuenca alta del río Tigre, había comunidades muy dispersas con bajo nivel de organización. Y adoptamos la estrategia de consolidar la organización, de fortalecer las existentes y de crear nuevas comunidades, particularmente nosotros creamos la comunidad de Yanayacu, que era la zona menos protegida, y a partir de ahí generamos un proceso de gestión de control de territorio y organización social, hasta llegar a conformar una organización conocida ahora como la asociación de pueblo ancestral quichua de Kawsak Sacha. Y esa estrategia ha tenido sus resultados muy concretos para las organizaciones, y esa es la estrategia que tomamos para defender nuestros territorios" (entrevista Alfredo Viteri, septiembre del 2012).
\end{abstract}

El Estado decía: "Ustedes tienen que demostrar que sí tienen comunidades", entonces dijimos: sí hay comunidades y luego por el miedo de que iban a venir a verificar eso, como eso nos dijeron que iban a venir a verificar las comunidades, entonces nos apresuramos a hacer un programa de nuevos asentamientos. Por eso se hizo también Yanayacu, se hizo aquí en Pavacachi, Nina Amarun. Bueno ahora en Victoria, Sisa y Atun Playa, es para justificar que tenemos nuestra posición" (entrevista Tito Merino, dirigente y presidente de la OPIP en varios períodos diferentes, Agosto de 2009).

Esta zona fronteriza de la que habla Alfredo Viteri tenía una gran importancia geoestratégica. Se trataba de un área de frontera de gran relevancia: atesoraba gran valor para los intereses de seguridad nacional del Estado, se hallaba escasamente poblada, constituía una de las áreas de selva mejor conservadas del país y con grandes recursos biológicos, y detentaba reservas probadas de petróleo (las compañías que, como vimos, habían estado realizando prospecciones años antes ya habían certificado su existencia, aunque no habían considerado rentable de momento su extracción). No es de extrañar que su ocupación efectiva se convirtiera en una de las prioridades de algunos líderes de la OPIP.

Para ello se retomó el viejo proyecto que el Estado había tenido previamente a través del DRIF de colonizar la cuenca baja del Curaray a través de una red de asentamientos. Así, en 1992 crearon la comunidad de Yana Yacu, en el límite sur de este territorio, promocionada por la familia Viteri Gualinga, como hemos visto en la cita de Alfredo, con gente de Sarayacu, selva arriba. En 1995 la OPIP, a través de Tito Merino, promovió la creación de Nina Amarum con familias de Lorocachi. Más adelante, como veremos, se crearían el resto de comunidades que aparecen el figura 1.

Pero para esta estrategia de crear y organizar a las comunidades hacía falta recursos económicos. Después del fracaso del INCRAE y su proyecto DRIF, las agencias de desarrollo estatales desaparecieron y, junto con el nuevo actor étnico, aterrizaron otras de carácter privado, las ONG. En un primer momento, y teniendo en cuenta el prestigio con el que todavía contaba la OPIP, fueron los dirigentes de esta organización los que utilizaron su poder de convocatoria para atraer proyectos de ONG de carácter nacional o internacional. Así, desde la OPIP atrajo a varias ONG a trabajar en Nina Amarum. Pero muchos de estas organizaciones, tal y como 
hemos sabido por entrevistas con dirigentes, dejaron de trabajar porque la gente estaba ocupada en otros proyectos y además querían que les pagasen por cualquier labor realizada. Estos "otros" proyectos son los del IQBSS, ONG fundada en los noventa por el líder Alfredo Viteri, aprovechando el prestigio adquirido, en una clara apuesta de oenegización ${ }^{28}$ de su estrategia. Nuestra hipótesis es que de esta manera buscaba la independencia de una organización, la OPIP, a la que controlar era ya difícil por las luchas internas existentes y el tamaño adquirido tras el éxito de 1992. Además, para finales de los noventa la OPIP empezaba a desprestigiarse y cada vez menos organizaciones trabajaban con ella por la complejidad y el mal funcionamiento interno $^{29}$. Su prestigio, su buen posicionamiento y su eficaz trabajo de gestión, convirtieron al IQBSS en un intermediario idóneo con el aparato del desarrollo y, por tanto, en un gran receptor de fondos. No se ha podido tener una información detallada del dinero y proyectos gestionados por dicha organización, pero una búsqueda por internet, sólo de la información pública aportada por financiadores de las cuales el IQBSS había sido contraparte desde 1999 hasta el 2011, otorgó como resultado $1.815 .337 €$ y 750.000 USD en diversos proyectos. Se trata de una información muy fragmentaria, pues la propia organización, a pesar de dar respuestas positivas en reiteradas ocasiones, nunca dio información al respecto. En cualquier caso, sólo con estas cifras queda patente la capacidad receptora de fondos. Por otro lado hay que remarcar que la gran totalidad de estos proyectos están centrados en esa importante franja de frontera de la cuenca baja del Curaray.

La acción del IQBSS tenía una doble intencionalidad muy útil para la estrategia territorial de Alfredo Viteri. Como buen conocedor de la situación, él sabía de la necesidad de acceso a recursos económicos de los indígenas de las comunidades. El éxito de su estrategia de fijar un núcleo poblacional mínimo estable en cada comunidad radicaba en la posibilidad de ofrecer esos recursos en forma de trabajo remunerado. La segunda pata de los proyectos del IQBSS encaminados a la estrategia territorial consistía en generar documentación (información cartográfica, normativas comunitarias y estatutos, planes de manejo del territorio, etc.) que pudiera facilitar el reconocimiento legal de las comunidades y sus territorios. Casi todos los proyectos que se pudieron chequear están relacionados con la gestión territorial y van encaminados a esta doble estrategia. Así, por un lado todos ellos generaban pequeños puestos de trabajo remunerados en diferentes vertientes vinculadas a la gestión del territorio como eran la puesta en marcha de huertos, la cría de animales para la alimentación, la cría de charapas (tortugas acuáticas) para repoblación, etc.; y por otro lado generaban una serie de información que sería de gran utilidad para el reconocimiento legal de dichas comunidades y sus territorios. Esta información consistía en cartografía, normativas comunitarias (la base de los estatutos para

28 Utilizaremos este término para referirnos a la estrategia de asumir la forma de ONG por parte de organizaciones y líderes indígenas para acceder a fondos de la cooperación. Este fenómeno, que también lo describe Mónica Martínez (2007) para el caso kuna en Panamá, no es lo más común. Lo más usual, como describe Víctor Bretón para los Andes ecuatorianos (2009), sería la mediación de las organizaciones indígenas, normalmente OSG, entre las comunidades y las agencias de desarrollo.

29 Al tratarse de plataformas que permiten acceder a recursos económicos y posicionamientos políticos, siempre ha existido una gran pugna en el seno de ellas. Estas rivalidades aumentaron con la entrada en la política formal del movimiento indígena a partir de la formación de Pachakutik en 1995. La OPIP sufrió especialmente estas luchas por tratarse de una organización grande y con mucha relevancia, tanto nacional como internacional, a partir de la marcha de 1992. Durante unos años se convirtió en un trampolín para acceder a otros espacios de poder (Antonio Vargas, de presidente de la OPIP pasó a presidir la CONAIE y después a ministro en el gobierno de Lucio Gutiérrez) y para manejar gran cantidad de recursos (llegó a tener: la Dirección de Aviación de la OPIP [DAO]; la caja de ahorro y crédito Palati; el centro de comercialización de arte y artesanía Yana Puma, las operadoras de turismo Atakapi Tour y Papangu Tour, el centro de gestión ambiental Fátima, el parque etnobotánico Omaere, etc.). Pero las fuertes luchas internas, la creación por parte de los líderes con mayor proyección de sus propias plataformas y la mala gestión fueron alejando a muchas organizaciones. En junio de 2001 un incendio arrasó con el edificio de la OPIP y con muchos de estos proyectos. Con el incendio desapareció toda la información, en lo que parece estar relacionado con las pugnas internas y un intento de borrar las huellas de un mal uso de los fondos de la cooperativa de crédito (Ortiz, 2003: 91). Finalmente ésta, junto con la gran mayoría de los proyectos, se fue a la quiebra. Esta trayectoria, sumada a las intromisiones del gobierno de Lucio Gutiérrez (2003-2005) a través de Antonio Vargas, acabó sumiendo a la OPIP en una crisis de prestigio y de representatividad de la que ya nunca se recuperaría. 
su posterior reconocimiento como comunidades) y planes de manejo (la base para la legalización del territorio).

Así, bajo esta estrategia se pudo culminar el viejo proyecto de asentar una red de poblaciones en esta franja fronteriza. Como vimos, Yana Yacu fue creada en 1992 y Nina Amarum en 1996, aunque todavía no tenían reconocimiento legal. Victoria, que se ubica río abajo de Lorocachi, fue creada en 2003. Finalmente, en año 2006, en plena vorágine de proyectos por parte del IQBSS se crearon dos comunidades más, Sisa y Atun Playa con familias de Lorocachi (ver figura 1). En cuanto a las características poblacionales de estas comunidades, daremos una serie de características sobre las mismas. La memoria oral hablaba de unas 20 familias en Lorocachi cuando se realizó su primera asamblea en 1985. En el primer dato más o menos fiable que tenemos, el censo del proyecto DRIF, habla de 176 personas distribuidas en 30 familias $^{30}$. Su población en la actualidad se mantiene parecida, con 150 habitantes según un censo del 2007. Esta comunidad ha supuesto el núcleo poblacional importante de la que han dependido el resto. En un primer momento Nina Amarum se formó con 6 familias, aunque en el 2012 ya sólo quedaban 4. Victoria, Sisa y Atiun Playa estaban formadas por tres familias cada una, todas ellas de una misma familia ampliada.

El reconocimiento legal de estas comunidades se realizó en 2007 con el apoyo del IQBSS, que fue quien les ayudó a reunir la información necesaria y a presentar los documentos en Quito. Para ello resultaría muy útil toda la información generada en la elaboración de los planes de manejo, pues, como pudimos observar analizando los expedientes de legalización, los estatutos provienen en parte de la normativa comunitaria y la cartografía presentada está elaborada por el IQBSS. Finalmente, la legalización global del territorio se logró en el 2011, cuando el gobierno de Rafael Correa legalizó 300.000 ha., la mayor legalización realizada desde 1992, para la asociación Kausak Sacha que conforman estas comunidades. Es importante remarcar que en este momento las élites indígenas ya han cambiado de estrategia. Ante el descenso de la cooperación provocado por la crisis financiera en E.E.U.U. y Europa, y la llegada al poder en Ecuador con Rafael Correa en el 2007 de un gobierno neodesarrollista que fortaleció enormemente el aparato estatal, estas élites pasan a aliarse con el gobierno. Así, Carlos Viteri, como dijimos, ocupó hasta finales del 2012 un cargo de rango de ministro como director del ECORAE y más tarde pasó a ser diputado por Alianza País, el partido de Correa. Alfredo Viteri era en el 2012 coordinador general del Consejo Quichua de Pastaza, entidad que sustituyó en 2010 a la OPIP. Con un carácter más técnico que político, y financiada directamente por el ECORAE, tenía el objetivo de diseñar un espacio de autonomía territorial indígena bajo la figura, recogida en la propia Constitución, de la Circunscripción Territorial Indígena (CTI) de los quichuas de Pastaza. En este momento Alfredo ya estaba abiertamente, y así nos lo confirmó en una entrevista, a favor de las explotaciones petroleras y de negociar las regalías desde la mejor posición posible. Y esta figura, la CTI, era, según él, la que proporcionaba una mejor posición para negociar la entrada de las petroleras.

Hemos visto cómo Alfredo Viteri utilizó la plataforma del IQBSS para atraer proyectos de carácter ambientalista que le permitieron llevar adelante su estrategia de establecimiento de una red de comunidades registradas legalmente y bajo su influencia en esa importante franja de frontera. Consideramos importante remarcar de nuevo el hecho de que este era el fin último de su actuación, y que los proyectos de ámbito conservacionista no eran más que el medio para llegar a ello. De hecho su éxito en la captación de fondos radicaba más en su posicionamiento, acceso a información, elaborado discurso y eficaz gestión burocrática, que en el éxito en sí de los proyectos en campo.

30 Este censo habla de familias blanco-mestizas. Sabemos que la base poblacional de aquel entonces es la misma que la de ahora, pero al tratarse de quichua-hablantes que se movían en medios militares mestizos en un momento en el que primaba la visión mestizo-campesina en los imaginarios desarrollistas (Martínez Valle, 2002: 333), seguramente muchos de los que a los ojos de los técnicos del INCRAE aparecían como blanco-mestizos eran quichua hablantes que querían acceder como mestizos a las promesas del desarrollo. 
Así, casi todos los proyectos del IQBSS en la primera década del 2000 están vinculados al territorio y al discurso ambientalista. La combinación de estos dos factores, bien articulados en un elaborado discurso en torno a las identidades de carácter ecológico ${ }^{31}$ posibilita el éxito de esta estrategia, pues a partir de la Conferencia de Río (1992) se reconoce a los pueblos indígenas en armonía con la naturaleza. Esta resignificación del mito del buen salvaje propicia el auge y la visibilidad de los pueblos indígenas y provoca la proliferación de proyectos dirigidos a la gestión de su territorio y de sus recursos naturales. Alfredo Viteri supo muy bien utilizar este discurso de corte ambientalista y acceder a los recursos económicos que de él se derivaban:

\begin{abstract}
"Nuestro territorio no es una cosa, ni un conjunto de cosas utilizables, explotables, ni tampoco un conjunto de recursos. Nuestro territorio, con sus selvas, sus montañas, sus ríos, sus lagunas y humedales, con sus lugares sagrados donde viven los supai [dioses protectores], con sus tierras negras, rojas y arenosas y sus arcillas, es un ente vivo que nos da vida, nos provee agua y aire; nos cuida, nos da alimentos y salud; nos da conocimientos y energía; nos da generaciones y una historia, un presente y un futuro; nos da identidad y cultura; nos da autonomía y libertad. Entonces, junto con el territorio está la vida y junto a la vida está la dignidad; junto al territorio está nuestra autodeterminación como pueblos. (...)
\end{abstract}

El territorio según la concepción indígena integra los elementos de la vida en toda su diversidad natural y espiritual: la tierra con su diversidad de suelos, ecosistemas y bosques, la diversidad de los animales y las plantas, los ríos, lagunas y esteros. Los ecosistemas naturales son considerados como hábitat de los dioses protectores de la diversidad de la vida y gracias a ellos se mantiene la integridad y el equilibrio (...) Nuestra tradición ancestral nos enseña que el territorio no es un recurso a ser explotado, es un espacio de vida. Hombres y mujeres somos una comunidad parte de ese espacio natural donde compartimos la vida con otros seres vivos en una relación de reciprocidad" (entrevista Alfredo Viteri, 2004).

Este relato de Alfredo Viteri muestra una cierta reificación de la cultura indígena, opacando en parte, bajo el concepto de ancestralidad, su dinamismo y convirtiéndola en un proceso ahistórico y monolítico que no corresponde con la realidad que hemos explicado. Se trataría, pues, de un discurso esencialista que esconde la permeabilidad y flexibilidad de las culturas indígenas para apropiarse de elementos de otras culturas de forma selectiva e instrumental y que "... no puede ser identificado con un corpus teórico definido, sino más bien con una actitud intelectual, que tiende a reificar los fenómenos analizados, minimizando o ignorando su diversidad interna, su carácter dinámico -y por lo tanto, histórico- o su compleja articulación con otros actores o fenómenos sociales." (Viola, 2001: 84)

Para terminar, es importante recalcar cómo en este discurso esencializado de carácter ecoidentitario la ancestralidad en el manejo de los territorios es nodal. Pero paradójicamente quienes se han apropiado de este discurso son, en realidad, colonos quichuas, mientras que, como veremos, otros "ancestrales" no existen para nadie.

31 Se trata de una convergencia entre los discursos étnicos esencializados y la ecología, una versión ecológica del mito del buen salvaje. Raymond Hames (2007) ha realizado una buena síntesis de las diferentes tendencias en el enfoque y estudio de esta nobleza ecológica. Para una historia de cómo se configuró esta alianza entre la etnicidad y el ambientalismo en el contexto político internacional consúltese a Astrid Ulloa (2004: 175-184). Este proceso de ecologización de las demandas y la retórica de los pueblos indígenas parece bastante extendido. Para el continente americano, entre otros, Andrea Muehlebach (2001) lo ha analizado en los discursos de delegados indígenas en el Grupo de Trabajo sobre Poblaciones Indígenas de la ONU, Mónica Martínez Mauri (2007) lo ha observado en el caso de los kunas en Panamá, Astrid Ulloa (2004) para las organizaciones de la Sierra Nevada de Santa Marta en Colombia, Beth Conklin y Laura Graham (1995) para el caso de organizaciones indígenas brasileñas. Centrándose en la Amazonía, William T. Vickers (1994) lo describió en el caso de los Siona-Secoya en Ecuador y Beth Conklin (2002) en la Amazonía Brasileña. 


\section{La invisibilización de los tagaere-taromenane}

Recordemos que explicamos que los huaorani, también llamados aucas (salvajes, en quichua), era un pueblo "no civilizado", con escasos y violentos contactos con el mundo occidental, que había ido ocupado la margen izquierda del río Curaray, llegando hasta sus cabeceras en la década de los cincuenta. Finalmente estos pueblos fueron contactados en los sesenta por los evangelistas del Instituto Lingüístico de Verano y sedentarizados en comunidades (Trujillo, 1981). Pero algunos grupos, como los tagaere, decidieron continuar ocultos y en 1968 se separaron de otro grupo, los piyemoire, que aceptaron ser sedentarizados y reubicados.

En cuanto a los tagaere-taromenane, conocidos también como pueblos "no contactados", "en aislamiento voluntario" u "ocultos" ${ }_{32}$, muy poco se sabe de ellos. Los tagaere, como hemos dicho, provienen de una escisión de uno de los grupos huaorani contactados y reubicados. Posiblemente en la actualidad se encuentren exterminados, principalmente por la guerra con otro de los grupos ocultos, los taromenane. De estos se sabe aún menos. Se trata de un grupo culturalmente relacionado con los huaorani, que posiblemente ha estado transitando por territorios a un lado y el otro de la frontera ecuatoriano-peruana. De hecho, y teniendo en cuenta que los huaoranis eran pueblos nómadas de cazadores-recolectores que se movían también por territorios de lo que hoy es Perú, no se descarta que alguno de los grupos haya llegado a territorio ecuatoriano huyendo de la agresiva frontera petrolera peruana. Tampoco se descarta que pudieran ser restos de pueblos záparas que, escapando de la explotación cauchera, se adentraron selva adentro y acabaron contactando con otros grupos huaorani (Cabodevilla, 2009: 145-161). El Ministerio del Ambiente tiene localizados a cuatro grupos que se mueven por sus amplias áreas de influencia, pero no se descarta que haya más.

En 1999 se declaró una zona dentro del parque Yasuní como intangible (758.051 ha), justo al norte del río Curaray. Esta área, teniendo en cuenta que son grupos nómadas y que, por el hecho de ser pueblos ocultos no conocen de límites ni fronteras, parece bastante insuficiente. Más aún, rodeada de otras comunidades y de bloques petroleros, se ha convertido en una trampa, una "jaula petrolera" (Pappalardo y de Marchi, 2013). Esto hace que los grupos ocultos se vean constreñidos y presionados en "una mínima parte de lo que consideraban su territorio" generando situaciones muy conflictivas (De Marchi, Aguirre y Cabodevilla, 2013: 40-41). Conflictividad que ha conducido a numerosos incidentes, dos de los cuales han significado matanzas muy trágicas para estos grupos, una en el 2003 en la que murieron 23 taromenanes, y la última en marzo del 2013, en la que se calcula, no se sabe a ciencia cierta, que fueron asesinados otros $30^{33}$. Asesinatos que en ambos casos fueron ejecutados por personas de la etnia huaorani. En estos conflictos, las disputas territoriales se ven agravadas por la intromisión de diferentes actores, como madereros y, principalmente, las petroleras, que achican cada vez más el territorio. La zona intangible tampoco se ve libre de intromisiones ilícitas (madereros, cazadores colonos o indígenas, turismo), muchas de ellas vinculadas a los huaoranis (Ibid.) ${ }^{34}$.

En este escenario, al sur de esta zona intangible, es donde se produjo el proceso de expansión quichua del que hemos hablado, encerrando aún más a estos pueblos ocultos y obstaculizando

32 Para Miguel Angel Cabodevilla (2009) es más correcto utilizar el término "ocultos", aunque tampoco éste sea totalmente adecuado. Según este autor no es verdad que no estén contactados, pues los contactos, a veces pacíficos y muchas veces violentos, con otros grupos huaorani han sido frecuentes en las últimas décadas. Tampoco sería apropiado hablar de "aislamiento voluntario" ya que este término estaría cargado de presunciones y tabúes, al identificar a estos pueblos viviendo felices en la selva y aislados, mientras que los indicios que nos llegan es que algunos de estos grupos se encuentran acorralados, no quieren continuar exactamente igual y cada vez establecen contactos más frecuentes para acceder a ciertos utensilios, como machetes u ollas, de los que han generado bastante dependencia.

33 Para más información acerca de la matanza de 2003 consúltese el libro de Miguel Ángel Cabodevilla, Randy Smith y Alex Rivas (2004); y para la del 2013 la publicación de Massimo de Marchi, Milagros Aguirre y Miguel Ángel Cabodevilla (2013).

34 Para profundizar en las problemáticas de la zona intangible ver, entre otros: Massimo de Marchi, Salvatore Pappalardo y Francesco Ferrarese (2011), Milagros Aguirre (2010) y Miguel Ángel Cabodevilla (2008, 2009). 
una posible propagación hacia el sur. No han sido muchos los conflictos que, por ahora, se han generado entre las comunidades quichuas y estos pueblos, pero sí se han producido avistamientos o indicios de su paso. Un comunero quichua de Lorocachi explicó cómo eran "molestados" por ellos en 1985:

"Si acá en esa laguna, ahí me fui hacer una casita y estuvimos viviendo ahí y molestaban mucho los huaoranis, estuvimos aquí y nos llamó el coronel para hacer una sesión a todita, todita, yo no estuve aquí, estuve afuera" (entrevista Jorge Cuji, agosto de 2009).

Se refiere a cuando el coronel Marco Miño les llamó en 1985 para conformar la comunidad de Lorocachi. Por aquel entonces cuenta que vivía en la laguna, al otro lado del Curaray, en lo que sería ya el Yasuní. Para aquella época la mayoría de los grupos huaoranis estaba ya contactada y reubicada, por lo que es muy probable que los huaorani de los que habla fuera alguno de los grupos ocultos. Por otro lado, la última vez que entramos en junio del 2012 detectamos mayor nerviosismo sobre el tema. Se hablaba algo más que otras veces de los taromenane, y un militar del batallón de Lorocachi, el mayor Enriquez, el 12 de junio del 2012 nos confirmó que estaban preocupados porque aparentemente algún grupo estaba realizando frecuentes incursiones al otro lado del Curaray y que esto podría generar conflictos con los quichuas. Incluso tenían pensado realizar una excursión de rastreo a ver si encontraban indicios de estas incursiones. Es muy probable que alguna vez estos conflictos que mencionaba el mayor Enriquez se produzcan, puesto que con la presión que reciben por el norte, debido a la explotación petrolera, la zona al sur del Curaray parece un sitio de expansión natural. De hecho, el Ministerio de Justicia, Derechos Humanos y Cultos, en el informe que realizó de cara al proceso de legalización del territorio de Kawsak Sacha, avisaba de los problemas que esta legalización puede generar y abogaba por una legalización provisional siempre y cuando los pueblos ocultos, protegidos por la Constitución, no fueran alterados ${ }^{35}$.

Pero a pesar de todo la legalización siguió adelante. De cualquier manera, para el Estado era mucho más cómodo tener a un interlocutor "válido" asentado en esos territorios. Los tagaeretaromenane no sólo son pueblos ocultos, sino también ocultados. No tienen voz ni nadie que les represente, y resultan tremendamente incómodos. De hecho, la desidia del Estado ante los conflictos generados con otros huaoranis, que recordemos ha conducido a dos grandes matanzas, está llevando a estos pueblos al exterminio.

\section{Conclusiones}

Podríamos resumir la historia de la Amazonía ecuatoriana, desde la colonia hasta la actualidad, en seis ciclos bien diferenciados. En los inicios de la instauración de la colonia española en la región equinoccial americana, se establece el primer frente de colonización amazónica, relacionado con un intenso pero breve boom de la minería aurífera. Se trata de un ciclo muy corto, que va desde la cuarta década del siglo XVI hasta finales del mismo siglo, de penetración masiva y brutal. Este ciclo finaliza bruscamente con el fin del auge minero, dejando tras de sí el abandono casi absoluto de esta región por parte de la sociedad civil blanco-mestiza (abandono que se extendería en cierta manera hasta la segunda mitad del siglo XIX) y una brusca caída demográfica de la población indígena de las zonas donde llegó la influencia de este frente de colonización.

El tercer período se extiende desde la salida de los jesuitas hasta mediados del siglo XIX y está caracterizado por el debilitamiento y fraccionamiento del frente misionero y un abandono total de este espacio por parte de las autoridades de Quito. El abandono conlleva un relativo período

35 Informe de adjudicación a favor de las comunidades de la asociación Kawsak Sacha. Consideraciones y resoluciones del Ministerio de Justicia, Derechos Humanos y Cultos. Quito. 2011. 
de paz para las poblaciones indígenas que queda reflejado en un lento crecimiento demográfico y expansión de las que sobrevivieron (y con ellas la expansión del quichua).

El cuarto ciclo comienza a mediados del siglo XIX y finalizará con la crisis del boom cauchero. Se trata de otro nuevo frente de colonización propiamente dicho (después del inicial del siglo XVI), produciendo una oleada de penetración, más lenta al principio y masiva en las dos últimas décadas del siglo, con unas consecuencias dramáticas para las poblaciones indígenas. Esta época significa la desaparición de muchas etnias y la potenciación de las dinámicas de quichuanización que habían comenzado en el siglo XVII. Además de este gran impacto en la configuración social de la Amazonía, otra de las consecuencias importantes de esta etapa es que este nuevo frente colonizador no está vinculado, como hasta ahora, a Quito (Ecuador), sino que se halla conectado, vía Iquitos, a Perú, potenciando las rivalidades entre estos dos países.

Después de este corto, pero dramático e intenso, ciclo del caucho, se produjo un nuevo abandono de este espacio. Gran parte de los colonos blanco-mestizos abandonaron este territorio tan pronto como llegó la crisis del caucho. Este abandono comienza a principios del siglo XX y finaliza con la guerra de 1941 contra Perú y el comienzo de las primeras operaciones de las compañías petroleras en la década de los cuarenta. Es en este momento en el que comienza a realizarse una integración real de esta región al espacio nacional, se abren vías de comunicación y la "modernidad" llega finalmente a estos confines. Es lo que hemos llamado el paso "del mítico Oriente a la Región Amazónica Ecuatoriana".

En cuanto a la cuenca del Curaray, hemos visto que los zápara eran los más antiguos pobladores de esta región. Resistieron aparentemente bastante bien el impacto de las misiones jesuíticas del siglo XVII-XVIII. Pero no corrieron la misma suerte con el impacto de la actividad cauchera, que acabó mermándolos drásticamente y potenciando dinámicas que favorecieron su aparente disolución dentro de la amalgama cultural quichua. Con la crisis del caucho, el Curaray comienza a quedar vacío de haciendas e indígenas "civilizados" en gran parte de su recorrido, dinámica de abandono que acaba de consolidarse con la Guerra de 1941 y el cierre de la frontera. Para estos momentos la identidad zápara ya estaba prácticamente diluida y oculta en el universo quichua. Paralelo a este proceso se produjo, como conquistadores de los territorios donde los záparas llevaban tiempo perdiendo su hegemonía, un avance en el Curaray de los huaorani.

Pero a partir de los años setenta comienza un proceso de (re)colonización de la cuenca baja del Curaray por colonos quichuas apoyados en el avance de los militares. Esta colonización comienza de una manera espontánea e intenta ser apuntalada por proyectos estatales de corte desarrollista, los cuales acaban siendo abandonados en los noventa por la llegada de las políticas neoliberales y la disminución del poder de acción del Estado. Es a partir de entonces que unas élites indígenas nacidas al calor de una emergencia de los movimientos indígenas retoman este proyecto y lo logran llevar a cabo. Para ello acceden a gran cantidad de recursos económicos de la cooperación articulando unos discursos étnicos esencialistas que giran en torno a las identidades de carácter ecológico y a la ancestralidad. Este concepto de "ancestralidad", que está muy presente en todos los discursos étnicos hoy en día, se trata más bien de un predicamento new age (Viola, 2011: 65) que no es capaz de superar ningún análisis histórico u antropológico mínimamente serio. Las élites de Pastaza articulan su discurso en torno a esta idea. El mismo nombre de la OSG ya lo deja claro: Pueblo Ancestral Kichwa Kawsak Sacha. Un análisis histórico nos muestra cómo los zápara eran los más antiguos pobladores de esta región. La actividad cauchera acabó mermándolos drásticamente y potenciando dinámicas que favorecieron su aparente disolución dentro de la amalgama cultural quichua. Con la crisis del caucho, el Curaray comienza a quedar vacío de haciendas e indígenas "civilizados" en gran parte de su recorrido, dinámica de abandono que acaba de consolidarse con la Guerra de 1941 y el cierre de la frontera ecuatoriano-peruana. Para estos momentos la identidad zápara ya estaba prácticamente diluida y oculta en el universo quichua. Paralelo a este proceso se produjo, como conquistadores de los territorios donde los záparas llevaban tiempo perdiendo su hegemonía, un avance en el Curaray de los huaorani. 
Y, finalmente, los quichuas llegan a partir de los setenta junto con los militares. Por lo tanto, estamos hablando de una "ancestralidad" de 30 años.

Con esto no queremos decir que las comunidades quichuas de la cuenca baja del Curaray no tengan derecho a estar allí, en absoluto. Empezando porque, como hemos explicado, es posible que muchos de los quichuas que han colonizado la zona tengan orígenes záparas. Más bien queremos remarcar la importancia de una mirada histórica para hacer frente a un esencialismo que potencia las fronteras étnicas, generando visiones homogeneizantes y atemporales, escondiendo la diversidad real y la historia de estos pueblos. Las culturas no deben ser percibidas como algo estático y homogéneo, sino como procesos dinámicos y espacios de transformación y negociación. Es precisamente en estos términos como puede explicarse la génesis de estas nuevas identidades, sin acabar reduciendo a las culturas indígenas, en el mejor de los casos, a un conjunto de simplezas y generalidades. No se puede representar a estos pueblos como una suerte de Adán y Eva que llevan viviendo felices desde la eternidad en una especie de paraíso prístino.

Es importante insistir en el hecho de que esta estrategia se fundamenta en un discurso ecoidentitario en el que "lo ancestral" es nodal para el manejo del territorio. La paradoja radica en que quienes se apropian de dicho discurso son colonos quichuas de otros lugares y que, por el contrario, los más próximos a la imagen de "ancestrabilidad" -los taromenane-, están invisibilizados, son ocultos y ocultados, pues no existen en tanto en cuanto no son sujetos políticos de interés ni para las organizaciones indígenas, ni para las ONG, ni para el Banco Mundial, ni para el Estado. Es la triste crónica de una muerte anunciada, la de los verdaderos usufructuarios del territorio, y de su inmolación ante el altar del desarrollo y los intereses crematísticos del Estado, las agencias de cooperación y la hegemonía del complejo quichua identitario. Este último, desde su posición subordinada en relación al establishment neoliberal que dicta las reglas del juego, estrategiza y mueve sus fichas en el resbaladizo tablero de la geopolítica amazónica de estas primeras décadas del siglo XXI.

Por último es importante remarcar como este proyecto hunde sus raíces en el proceso de ecuatorianización de la Amazonía interior tras la fijación de las fronteras en 1942 y como nos encontramos ante una continuidad histórica en el mismo. La impotencia para la integración de la Amazonía ecuatoriana fue una constante tanto en la colonia como en la república. Es lo que hemos llamado el "sueño oriental", la obsesión por la nacionalización de estos territorios que no se dio, en general, hasta la segunda mitad del siglo XX con la llegada de la actividad petrolera. Pero en territorios alejados y de difícil acceso como la cuenca baja del Curaray este "sueño" no llegó hasta el cambio de siglo. Fue entonces cuando por fin esta región se articuló al Estado nacional, pero paradójicamente no lo hizo por acción del Estado, que había fracasado en el intento, sino, signo de los tiempos neoliberales, por acción de unas élites indígenas bien articuladas en el mundo global en el que vivimos. 


\section{Bibliografía}

Acosta-Solís, Misael. 1992, "Por la conservación de la Amazonía”, en Revista Geográfica, No. 115, pp. 77-84.

Andrade, Karen. 2004, "El papel del ECORAE en la Región Amazónica Ecuatoriana. Un ejemplo de crisis de gobernabilidad democrática en el Ecuador.” Tesis de maestría, Facultad Latinoamericana de Ciencias Sociales (FLACSO), Ecuador. Maestría de Ciencias Sociales con mención en Estudios Ambientales.

Assies, Willem. 2000, "Indigenous Peoples and Reform of the State in Latin America", en: Assies, Willem, Gemma Van Der Haar \& André Hoekema (Eds.), The Challenge of Diversity. Indigenous Peoples and Reform of the State in Latin America, Thela Thesis, Amsterdam, pp. 3-21.

Báez, Sara. 2004, "Sistematización de la experiencia de manejo territorial de los pueblos kichwas de Pastaza", en Báez, Sara; Pablo Ospina y Galo Ramón, Una breve historia del espacio ecuatoriano, Camaren, Quito, pp. 189-229.

Barclay, Frederica. 1998, "Sociedad y economía en el espacio cauchero ecuatoriano de la cuenca del río Napo, 1880-1930”, en García Jordán, Pilar (Ed.), Fronteras, colonización y mano de obra indígena en la Amazonía Andina (Siglos XIX-XX), Fondo editorial PUCE y Universitat de Barcelona, Lima.

Barrera, Augusto. 2001, Acción colectiva y crisis política. El movimiento indígena ecuatoriano en la década de los noventa, Abya-Yala y OSAL/CLACSO, Quito.

Bebbington, Anthony y Thomas Carroll. 2000, "Induced Social Capital and Federations of the Rural Poor". Social Capital Initiative, Working Paper N. ${ }^{\circ}$ 19, World Bank, Washington.

Bengoa, José. 2000, La emergencia indígena en América Latina, Fondo de Cultura Económica de México, México.

Bilhaut, Anne-Gaël. 2011, El sueño de los záparas. Patrimonio onírico de un pueblo de la alta Amazonía, AbyaYala y FLACSO-Ecuador, Quito.

Bretón, Víctor. 2012, Toacazo. En los andes equinocciales tras la reforma agraria, FLACSO y Abya-Yala, Quito. 2009, "La deriva identitaria del movimiento indígena en los Andes ecuatorianos o los límites de la etnofagia", en: Martínez, Carmen (Ed.), Repensando los movimientos indigenas, Flacso Ecuador, Quito, pp.69-121.

Bruce, John Ronald. 1999, "Las relaciones Ecuador y Perú: Una perspectiva histórica”, en: Ecuador y Perú. Horizontes de la negociación y el conflicto, FLACSO-Ecuador, Quito, pp. 89-110.

Cabodevilla, Miguel Ángel. 2009, El exterminio de los pueblos ocultos, CICAME, Quito.

1999, Los huaorani en la historia de los pueblos del Oriente, Cicame, Quito.

Cabodevilla, Miguel Ángel, Randy SMITH y Alex RIVAS. 2004, Tiempos de guerra: waorani contra taromenane, Abya-Yala, Quito.

Conklin, Beth A. 2002, "Shamans versus pirates in the Amazonian treasure chest", en: American Anthropologist 104, pp. 1050-1061.

Conklin, Beth A. y Laura R. Graham. 1995, "The shifting middle ground: Amazonian Indians and eco-politics", en: American Anthropologist 97, pp. 695-710.

Criollo, María Cristina. 2007, "Manejo de recursos naturales en las propuestas de autonomía indígena amazónicas: caso OPIP y el plan de vida en la comunidad de San Jacinto de Pindo, provincia de Pastaza", Tesis de Maestría en Estudios Socioambientales, FLACSO, Quito.

Dall'Alba, Leonir. 1992, Pioneros, nativos y colonos. El Dorado en el siglo XX, Abya-Yala, Quito.

De Castro, Sergio. 2009, "Sarayacu: libertad, tierra, cultura. La lucha por la autonomía en una comunidad kichwa de la amazonía ecuatoriana”, en: Libre pensamiento, 60, pp. 60-69.

De Marchi, Massimo; Milagros Aguirre y Miguel Ángel Cabodevilla. 2013, Una tragedia ocultada, CICAME, Quito.

Del Pilar, Delia. 2009, "Fronteras, etnocidio y comercio mundial. La Amazonía peruana-colombiana durante el boom cauchero.", en: Revista de Estudios Avanzados, 11, pp. 79-98.

Deler, Jean-Paul. 2007, Ecuador: del espacio al Estado Nacional, Universidad Andina Simón Bolivar, Instituto Francés de Estudios Andinos y Corporación Editora Nacional, Quito.

Díaz-Polanco, Héctor. 2006, Elogio de la Diversidad. Globalización, Multiculturalismo y Etnofagia, Siglo XXI, México.

DRIF. 1990, "Proyecto Desarrollo Rural Integral en Faja de Frontera", Proyecto Lorocachi. Ecuador: MAG, INCRAE, DRIF.

Esvertit, Natalia. 2008, La incipiente provincia. Amazonía y Estado ecuatoriano en el siglo XIX, Universidad Andina Simón Bolivar-Corporación Editora Nacional, Quito. 
Gamarra, María del Pilar. 1996, "La frontera nómada: frentes y fronteras económicas en el proceso cauchero ecuatoriano (1870-1920)", en: Procesos, no 9, UASB/TEHIS, pp. 39-79.

García Jordán, Pilar. 2001. "En el corazón de las tinieblas... del Putumayo, 1890-1932. Fronteras, caucho, mano de obra indígena y misiones católicas en la nacionalización de la Amazonía”, en: Revista de Indias, vol. LXI, $\mathrm{n}^{\circ} 223$, pp. 591-617.

García O.C.D, Lorenzo. 1999, Historia de las misiones en la Amazonía Ecuatoriana, Abya Yala, Quito.

Grey Postero, Nancy. 2007, Now We Are Citizens, Stanford University Press, Stanford.

Gupta, Akhil y Aradhana Sharma. 2006, "Globalization and Postcolonial States", en: Current Anthropology N. 47, Vol. 2, pp. 277-307.

Hale, Charles. 2002, "Does Multiculturalism Menace? Governance, Cultural Rights and the Politics of Identity in Guatemala", en: Journal of Latin American Studies 34 (3), pp. 485-524.

Hale, Charles. 2004,"El protagonismo indígena, las políticas estatales y el nuevo racismo en la época del indio permitido". Ponencia en la conferencia: Construyendo la paz: Guatemala desde un enfoque comparado, organizada por la Misión de verificación de las Naciones Unidas en Guatemala (MINUGUA) 27-29 de octubre.

Hames, Raymond. 2007, “The Ecologically Noble Savage Debate”, en: Annual Review of Anthropology, 36, pp. 177-190.

Hudelson, John Edwin. 1987, La cultura quichua de transición. Su expansión y desarrollo en el alto Amazonas, Abya-Yala, Quito.

Ibarra, Hernán. 1999, La Guerra de 1941 entre Ecuador y Perú, una reinterpretación, Centro Andino de Acción Popular, Quito.

Larrea, Fernando. 2010, "Estado neoliberal y movimiento indígena: neoindigenismo, biopolítica y representación”, Tesis de maestría, Facultad Latinoamericana de Ciencias Sociales (FLACSO), Quito.

Livi Bacci, M. 2012, El Dorado en el pantano. Oro, esclavos y almas entre los Andes y la Amazonia. Madrid: Marcial Pons Historia.

Maldonado, Luis (Ed.). 1988, Las Nacionalidades indigenas en el Ecuador, CONAIE, Quito.

Martínez Mauri, Mónica. 2007, "De Tule Nega a Kuna Yala. Mediación, territorio y ecología en Panamá, 19032004", Tesis Doctoral, Universidad Autónoma de Barcelona-École des Hautes Études en Sciences Sociales, Barcelona-París.

Martínez Novo, Carmen. 2006, Who Defines Indigenous? Identities, Development, Intellectuals and the State in Northern Mexico, Rutgers University Press, New Brunswick.

Martínez-Sastre, Javier. 2014, "El paraíso en venta. Desarrollo, etnicidad y ambientalismo en la frontera sur del Yasuní (Amazonía ecuatoriana)", Tesis Doctoral, Departament d'Història de l'Art i Història Social, Universitat de Lleida, Lleida.

Martínez Valle, Luciano. 2002, "Desarrollo rural y pueblos indígenas: una aproximación al caso ecuatoriano", en: Pérez Correa, Edelmira y José María Sumpsi (Eds.), Políticas, instrumentos y experiencias de desarrollo rural en América Latina y la Unión Europea, FODEPAL, MAPA y AECI, Madrid, pp. 327-344.

Montoya, Rodrigo (Ed.) 2008, Voces de la tierra: reflexiones sobre movimientos políticos indígenas en Bolivia, Ecuador, México y Perú, Editorial de la UNMSM, Lima.

Muehlebach, Andrea. 2001, "Making place at the United Nations: indigenous cultural politics at the UN Working Group on Indigenous Populations", en: Cultural Anthropology 16, pp. 415-448.

Muratorio, Blanca.1998, Rucuyaya Alonso y la historia social y económica del alto Napo. 1850-1950, Abya Yala, Quito.

Oberem, Udo.1980, Los Quijos. Historia de la transculturación de un grupo indígena en el Oriente Ecuatoriano, Instituto Otavaleño de Antropología, Otavalo.

Ortiz Batallas, Celia. 2006, Indios, militares e imaginarios de nación en el Ecuador del siglo XX, Abya-Yala, Quito.

Pappalardo Salvatore, De Marchi Massimo. 2013, “Geografia de la Zona Intangible Tagaeri Taromenane: ¿una jaula petrolera?", en: URL: www.geoyasuni.org (consultado el 25/12/2013)

Porras, María Elena. 1987, Gobernación y Obispado de Mainas. Siglos XVII y XVIII, Abya-Yala, Quito.

Radcliffe, Sarah. 1998, "Frontiers and popular nationhood: geographies of identity in the 1995 Ecuador-Peru border dispute", en: Political Geography, Vol. 17, No. 3, pp. 273-293.

Reeve, Mary-Elizabeth. 2002 [1988], Los quichua del Curaray. El proceso de formación de la identidad, AbyaYala, Quito. 
Sawyer, Suzana. 2004, Crude chronicles: indigenous politics, multinational oil, and neoliberalism in Ecuador, Duke University Press, Durham.

Tamariz, Maria Eugenia y Xavier Villaverde. 1997, Diagnóstico de la tenencia de la Tierra en las provincias de Sucumbios y Napo, FEPP, Quito.

Taussig, Michael. 1984, "Culture of Terror-Space of Death. Roger Casement's Putumayo Report and the Explanation of Torture", en: Comparative Studies in Society and History, Vol. 26, No. 3, pp. 467-497.

Taylor, Anne Christine. 1994, "El Oriente Ecuatoriano en el siglo XIX: el otro litoral", en: Maiguashca, Juan (Ed.), Historia y región en el Ecuador: 1830-1930, FLACSO-Corporación Editora Nacional, Quito, pp. 1767.

Trujillo, Jorge. 2001, Memorias del Curaray, FEPP, Quito.

1981, Los obscuros designios de Dios y del Imperio, Editorial el Conejo, Quito.

Ulloa, Astrid. 2004, La construcción del nativo ecológico. Complejidades, paradojasy dilemas de la relación entre los movimientos indígenas y el ambientalismo en Colombia, Instituto Colombiano de Antropología e Historia -ICANH-, Bogotá.

Uribe, Tomás. 2013, “Caucho, explotación y guerra: configuración de las fronteras nacionales”, en: Memoria y sociedad, $\mathrm{n}^{\circ} 17$, pp. $34-48$.

Van Cott, Donna Lee. 2007, “Latin America’s Indigenous Peoples”, en: Journal of Democracy, Vol. 18 (4), pp. 127-142.

Vickers, William T. 1994, "From opportunism to nascent conservation. The Case of the Siona-Secoya", en: Human Nature 5 (4), pp. 307-337.

Villamil, Héctor. 1995, "El manejo del conflicto con las petroleras. El caso ARCO-OPIP”, en: Varea, Ana María (Ed.) Marea Negra en la Amazonía, Abya-Yala, Quito, pp. 339-336.

Villavicencio, Manuel. 1858, Geografía de la República del Ecuador, Imprenta de Robert Graighead, New York. Viola, Andreu. 2001, ;Viva la coca, mueran los gringos! Movilizaciones campesinas y etnicidad en el Chapare (Bolivia), UB, Barcelona.

Viteri, Alfredo. 2004, "Tierra y territorio como derechos", en Pueblos. Revista de información y debate, diciembre, en: URL: www.revistapueblos.org (consultado el 25/11/2012)

Whitten, Norman. 1987, Sacha Runa. Etnicidad y adaptación de los quíchua hablantes de la Amazonía Ecuatoriana, Abya-Yala, Quito.

Yashar, Deborah. 2005, Contesting citizenship in Latin America: The rise of indigenous movements and the postliberal challenge, Cambridge University Press, Cambridge. 